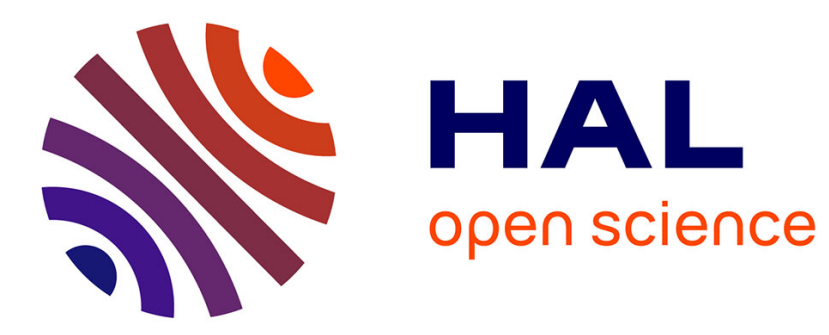

\title{
(Photo)Thermal Stimulation of Functional Dithiolene Complexes in Soft Matter
}

\author{
Franck Camerel, Marc Fourmigué
}

\section{To cite this version:}

Franck Camerel, Marc Fourmigué. (Photo)Thermal Stimulation of Functional Dithiolene Complexes in Soft Matter. European Journal of Inorganic Chemistry, 2020, 2020 (6), pp.508-522. 10.1002/ejic.201901118 . hal-02498322

HAL Id: hal-02498322

https://hal-univ-rennes1.archives-ouvertes.fr/hal-02498322

Submitted on 30 Mar 2020

HAL is a multi-disciplinary open access archive for the deposit and dissemination of scientific research documents, whether they are published or not. The documents may come from teaching and research institutions in France or abroad, or from public or private research centers.
L'archive ouverte pluridisciplinaire HAL, est destinée au dépôt et à la diffusion de documents scientifiques de niveau recherche, publiés ou non, émanant des établissements d'enseignement et de recherche français ou étrangers, des laboratoires publics ou privés. 


\title{
(Photo)Thermal Stimulation of Functional Dithiolene Complexes in Soft Matter
}

\author{
Franck Camerel* and Marc Fourmigué*
}

Univ Rennes, CNRS, ISCR (Institut des Sciences Chimiques de Rennes) - UMR 6226, Campus de Beaulieu, 35042 Rennes, France.

Emails: franck.camerel@univ-rennes1.fr; marc.fourmigue@univ-rennes1.fr

https://iscr.univ-rennes1.fr/macse/

\section{Biography}

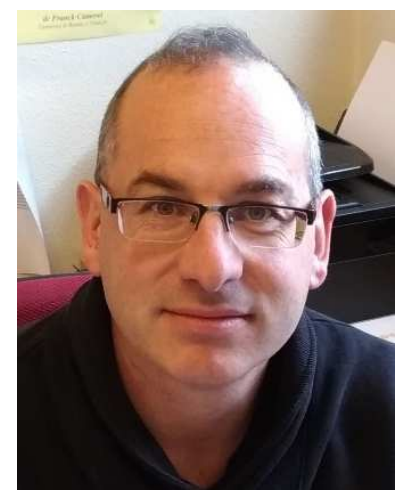

Franck Camerel received his $\mathrm{PhD}$ degree from the University of Nantes (France) in 2001 for his works on mineral complex fluids. After a postdoctoral stay at Max-Planck-Institute of Colloids and Interfaces (Potsdam) on ionic self-assembly processes, he joined the CNRS in 2003 in Strasbourg to design luminescent liquid crystals and organogelators. Since 2009, he started an independent research at ISCR (Rennes) to develop optically active metal complexes for applications in optoelectronic and biotechnologies. Beyond liquid crystals and gels, he is particularly interested in photothermal effects to develop new stimuli-responsive materials.

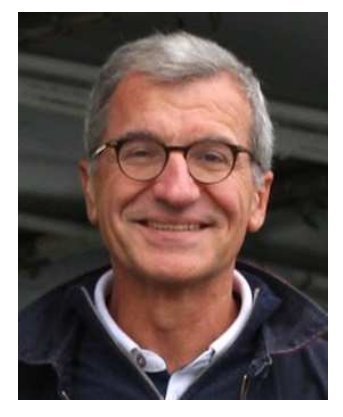

Marc Fourmigué received his Ph.D. in Material Sciences from University Paris XI (France) in 1988 and got his CNRS position in 1990 in Orsay (Lab. Physique des Solides). After positions in Nantes (IMN, 1995-2001) and Angers (Moltech, 2002-05), he moves to the Institut des Sciences Chimiques de Rennes (ISCR) in 2006 where he is the current director since 2017. He was the recipient of the SCF Coordination Chemistry Prize in 1997. His main research activities are related to the chemistry of the organic solid state, including molecular (semi)conductors and magnets, coordination chemistry, crystallography, non-covalent interactions (halogen, chalcogen bonding). 


\begin{abstract}
Square-planar bis(dithiolene) complexes are characterized with a planar delocalized structure and a strong and tunable Near Infra-Red (NIR) absorption; they are highly stable under laser irradiation and their conversion efficiency (light to heat) reaches up to 40-50\%. Their involvement in soft matter, namely liquid crystals, gels and nanoparticles, opens many possibilities to control the actual state of a material, particularly under light irradiation. Thus, liquid crystalline phases can easily be modified, (i) with temperature to modulate the extended of magnetic interactions of paramagnetic complexes, or (ii) under laser irradiation to unravel these remarkable photothermal properties, toward the development of light-responsive materials. Dithiolene complexes can be also functionalized to produce very effective gelation agents, while the photothermal effect can be used to destabilize at will their supramolecular organization. Besides photothermal therapy, photo-controlled drug delivery and bioimaging were also considered to develop new therapeutic agents by combining chemotherapy and phototherapy. Thus, hydrophobic complexes were accordingly designed for their encapsulation in block copolymer nanoparticles for photothermal therapy and photo-controlled drug delivery under laser irradiation. This class of complexes can be also used as exogenous contrast agents for photoacoustic bioimaging.
\end{abstract}




\section{Introduction}

At the heart of the field of molecular and materials science is the quest for understanding, through observation of matter at ever-smaller scales, how new physical properties emerge when large numbers of constituents interact with each another, for example in the crystalline state or in soft matter. Our ability to control the electronic and structural states of such molecules and materials, by driving or switching their state represents not only intellectual challenges but also societal challenges, with impact on information and communication technology, global renewable energy, health and biomedicine. In that respect, light is an invaluable tool for modifying, reversibly or irreversibly, the actual states of molecules and materials. We describe here our efforts along these lines, more specifically focused on a family of electro- and photoactive molecular complexes, namely metal-bis(dithiolene) complexes. ${ }^{[1]}$ While their molecular properties (electronic structure, optical absorption, redox behavior) and their electronic properties in the crystalline state (magnetism, conductivity, ...) ${ }^{[2]}$ have been extensively investigated over six decades, their introduction in the broad domain of soft matter (thermotropic liquid crystals, gels, polymers, nanoparticles) is still in its infancy. In these intermediate states of matter, weaker intermolecular interactions give the systems an enhanced sensitivity to external stimuli, temperature of course but also light. This is all the more pertinent with dithiolene complexes, particularly the square planar metal-bis(dithiolene) ones since they can exhibit a very strong absorption in the NIR (Near Infra-Red) region, and more precisely in the transparency window of biological media. Note that similar approaches aimed at taking advantage of these remarkable optical properties, but in the crystalline solid state, were particularly investigated by Naito et al., ${ }^{[3]}$ unraveling new concepts such as reversible optical doping toward photomagnetic conductors and giant photoconductors, with a sharp wavelength selectivity and a nonlinear dependence on the light intensity in their photoresponse. In the following review, we will describe first dithiolene complexes in general with their specific electronic properties. It will be followed by recent results, from our group or others, on their involvement in liquid crystals, gels and finally nanoparticles, with a specific focus on their behavior under thermal stimulation and light irradiation.

\section{Dithiolene complexes. Structural and electronic properties.}

Conjugated 1,2-dithiolate ligands (Figure 1) are the basis units for the elaboration of dithiolene complexes. The ligand itself has a so-called non-innocent character as it can by oxidized into the radical anion species and the neutral 1,2-dithioketone (or dithiete form) (Figure 1a). When associated with typically a $\mathrm{d}^{8}$ metal cation $\left(\mathrm{Ni}^{2+}, \mathrm{Au}^{3+}\right)$, it gives rise to a 
diamagnetic, square-planar bis(dithiolene) complex with a dianionic $\left(\mathrm{Ni}^{2+}, \mathrm{Pt}^{2+}\right)$ or monoanionic charge $\left(\mathrm{Au}^{3+}\right)$. The non-innocent character of the ligands gives the complexes a rich electrochemical behavior: Nickel complexes are known with charge $-2,-1$ (radical), $0,+1$ (radical) and Gold complexes with charge $-1,0$ (radical), +1 (Figure 1b). Numerous dithiolate ligands have been described and the most usual ones are collected in Figure 1c with their acronyms (Figure 1c).

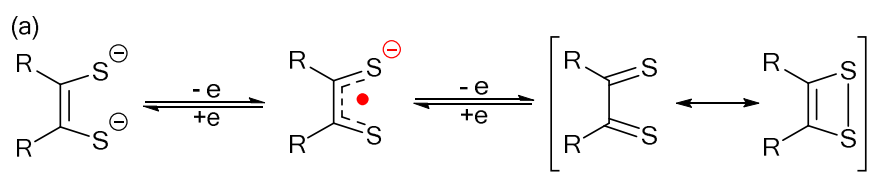

(b)

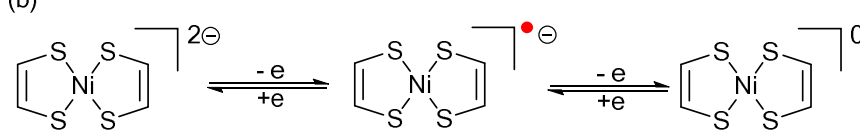

$\mathrm{Ni} 2+\mathrm{d} 8$

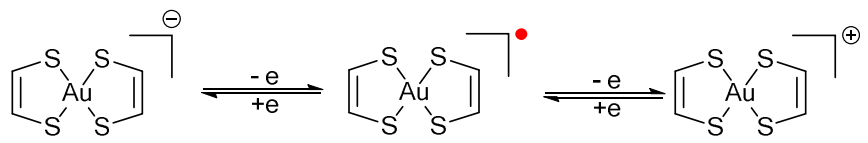

Au3 $+d 8$

(c)<smiles>N#CC([S-])=C([S-])[S-]</smiles><smiles>[O-]c1sc(=S)sc1[S-]</smiles><smiles>[R][R17]1sc(=S)c([Se-])c1[O-]</smiles><smiles>[R2]n1c([Se-])c([Se-])n([R])c1=S</smiles><smiles>[O-]C1=C([S-])SCCS1</smiles><smiles>[O-]c1ccccc1S</smiles><smiles>[O-]C(=C[Se])c1ccccc1</smiles><smiles>[O-]C([Se])=C(c1ccccc1)c1ccccc1</smiles>

Figure 1. (a) The non-innocent 1,2-ethylenedithiolate ligand, (b) the electroactive dithiolene complexes and (c) molecular structures of well-known dithiolene ligands.

The electronic structure of on isolated dithiolene complex can be easily understood in a very simplified approach, as the interaction of the partially filled metal $\mathrm{d}$ orbitals with the $\pi$ type HOMOs of the two dithiolene ligands, represented here (Figure 2a) as their formal inphase and out-of-phase combinations, essentially degenerated. For a dianionic nickel complex (Figure $2 b$ ), the in-phase ligand combination is orthogonal to any $d$ metal orbital, giving a HOMO-1 orbital for the complex without any metal contribution, while the out-of-phase ligand orbital combination overlaps with the $d_{x z}$ metal orbital, to give the HOMO orbital of the complex. Because of a large HOMO-LUMO gap, dianionic nickel complexes absorb only in the visible range. Upon oxidation to the radical anion state (Figure 2c), a (SOMO-1)-SOMO 
optical transition becomes possible at much lower energy $\left(\Delta \mathrm{E}_{2}\right)$, giving these radical species a strong absorption in the Near Infra-Red (NIR) range, from 900 to $1600 \mathrm{~nm}$, with absorption coefficients $\varepsilon$ around $30000 \mathrm{M}^{-1} \mathrm{~cm}^{-1}{ }^{[4,5]}$

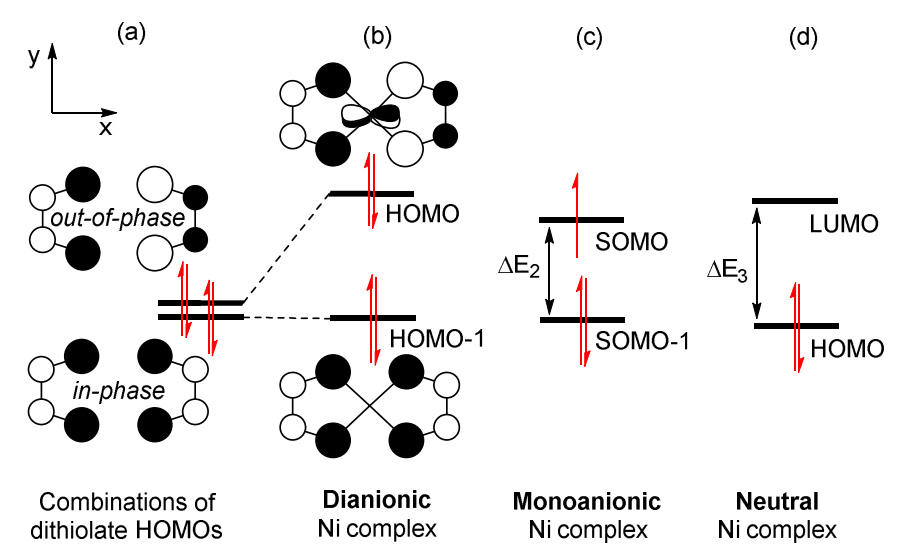

Figure 2. Simplified electronic structure of Nickel bis(dithiolene) complexes. (a) The degenerated linear combinations of the dithiolene ligand's HOMOs. (b) Interaction of in-phase and out-of-phase combinations of ligand's HOMO with metal d orbitals is only symmetry adapted with the metal dxz orbital (antibonding combination is represented). (c) $1 \mathrm{e}^{-}$oxidation to monoanionic complex allows for a SOMO-1 $\rightarrow$ SOMO transition at low energy $\left(\Delta \mathrm{E}_{2}\right)$. (d) $2 \mathrm{e}^{-}$oxidation to neutral complex allows for a HOMO $\rightarrow$ LUMO transition at low energy $\left(\Delta \mathrm{E}_{3}\right)$.

Note that the most electron-rich ligands (dithiolene ligands with electron-donating group, EDG) provide complexes with NIR transition at the lowest energies. It is the consequence of the destabilization of both the in-phase and out-of-phase combinations of ligand orbitals, providing a weakened interaction with the metal $\mathrm{d}_{\mathrm{xz}}$ orbital and hence smaller $\Delta \mathrm{E}_{2}$ values. Further oxidation of the radical anion to air-stable, neutral nickel complexes (Figure 2d) is possible indeed only with such EDG-substituted ligands. A low energy absorption $\left(\Delta \mathrm{E}_{3}\right)$, now of HOMO-LUMO character, is still observed but systematically blue shifted, relative to that of the radical anion complex $\left(\Delta \mathrm{E}_{3}>\Delta \mathrm{E}_{2}\right)$. On the other hand, the absorption coefficient $\varepsilon$ of the neutral complexes is twice the one of the radical anions. ${ }^{[6]}$

Among the different applications of such bis(dithiolene) complexes, the search for conducting materials with metallic (or even superconducting) properties has concentrated numerous efforts. They concern essentially mixed-valence radical anion salts based on the monoanionic $\mathrm{Ni}(\mathrm{Pd}, \mathrm{Pt})$ complexes such as $\left[\mathrm{Ni}(\mathrm{dmit})_{2}\right]^{1-, 0.5-, 0}$, associated with electronically inert onium cations. ${ }^{[2]}$ More recent examples address neutral single-component conductors (without any counter ion) derived from radical gold bis(dithiolene) complexes, ${ }^{[7]}$ from solid 
solutions of neutral nickel (diamagnetic) and gold (paramagnetic) complexes, ${ }^{[8]}$ or even from neutral and closed-shell nickel complexes (under high pressures). ${ }^{[9]}$

Taking advantage of the very strong NIR absorption of these complexes was originally considered for use as solid dye Q-switch for a $\mathrm{Nd}$ laser using the neutral complex bis(dimethylaminodithiobenzil)nickel) and a styrene-isoprene block copolymer. ${ }^{[10,11]}$ It was also reported as a near-IR dye for liquid crystal device applications because of a good solubility in Liquid Crystal (LC) host, low impact on the inherent order of the LC phase, good thermal and chemical stability, and a large absorbance maximum tunable by structural modification over a broad range of the near-IR region. ${ }^{[12]}$ Mueller-Westerhoff ${ }^{[13]}$ was the first to mention the possible use of dithiolene complexes with strong NIR absorption as promising candidates for photothermal therapy (PTT). PTT is a minimally invasive and harmless therapeutic methodology which employs hyperthermia generated by photothermal agents from laser energy to kill malignant cells. Such a PTT prefers near-infrared (NIR, $\lambda=700-1100 \mathrm{~nm}$ ) radiation with the typical tissue penetration of several centimeters in biological tissues. ${ }^{[14]}$ Such complexes have also found applications for photothermal laser printing on thin films. ${ }^{[15]}$ All these earlier results let us infer that dithiolene complexes could be very efficient to control, through a NIR light stimuli, the actual state of sensitive supramolecular assemblies such as liquid crystals, gels and nanoparticles. We describe in the following our journey along these three lines.

\section{Liquid crystals}

With their square planar shape, metal-bis(dithiolene) complexes are good platforms to develop mesogens and especially discotic mesogens. The first liquid crystalline dithiolene complexes were described by Giroud-Godquin and Mueller-Westerhoff (M=Ni, Pt, Pd) and they marked the beginning of the interest in metal-containing liquid crystalline materials (metallomesogens). ${ }^{[16,17]}$ Two carbon chains $(n=4,8,10)$ have been grafted on the metalbis(monophenylethylen-1,2-dithiolate)metal, $\left[\mathrm{M}(\text { mphedt })_{2}\right]^{0}$, in trans configuration (Figure 3). The molecules have rod-like shape and can be classified in the family of the calamitic mesogens. With short carbon chains $(n=4)$, the nickel and the platinum complexes display a nematic phase $(\mathrm{N})$ in the temperature range $117-175^{\circ} \mathrm{C}$ and $158-202{ }^{\circ} \mathrm{C}$, respectively. Longer chains length, as expected, stabilizes the formation of smectic phases (Sm), in which tilted molecules are organized into layers $(\mathrm{SmC})(\mathrm{M}=\mathrm{Ni}, \mathrm{n}=8$ : Cr $121 \mathrm{SmC} 191 \mathrm{I}, \mathrm{n}=10$ : Cr 103 SmC 189 I; $\mathrm{M}=\mathrm{Pt}, \mathrm{n}=8$ : Cr 150 SmC 209 I, $\mathrm{n}=10$ : Cr 140 SmC 202 I). Curiously, the palladium complexes were found to be deprived of mesomorphic properties and only crystalline 
structure have been detected. No satisfactory explanation has been found to explain this particular behavior. It can already be observed that the choice of the metallic center is noninnocent and the nature of the metal strongly affects the mesomorphic behavior.

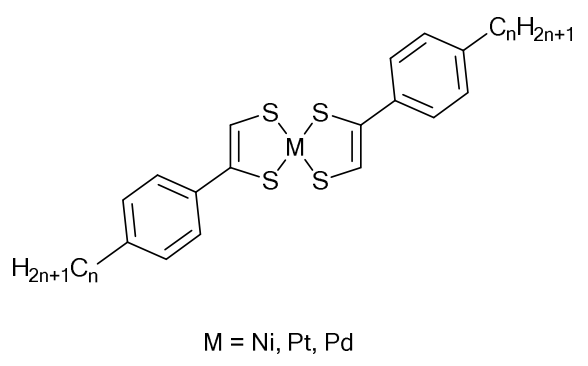

Figure 3. Molecular structure of the calamitic metal-bis(dithiolene) complexes

The use of branched chains decreases the crystal-to-mesophase temperature but also the thermal stability. ${ }^{[18]}$ With the racemic 2-methyloctyl chains, the nickel-bis(dithiolene) complex displays two mesophases (Cr 98 SmC 103 N 118 I) and with the chiral S-5-methylheptyl chains, a chiral SmC phase is observed between $119{ }^{\circ} \mathrm{C}$ and $159{ }^{\circ} \mathrm{C}$. Metal bis(dithiolene) complexes substituted with four or eight aliphatic chains at the periphery have also been developed $(\mathrm{R}=$ $\left.\mathrm{OC}_{n} \mathrm{H}_{2 \mathrm{n}+1}, \mathrm{R}^{\prime}=\mathrm{H} ; \mathrm{R}=\mathrm{R}^{\prime}=\mathrm{OC}_{\mathrm{n}} \mathrm{H}_{2 \mathrm{n}+1}\right)$. Long carbon chains have been grafted at the periphery of bis(1,2-diphenylethylen-1,2-dithiolate)metal $\left[\mathrm{M}(\mathrm{dphedt})_{2}\right]^{0}$ derivatives (Figure 4). These molecules have a disk-like shape and are now expected to exhibit columnar mesophases.<smiles>[R]c1ccc(C2=C(c3ccc([R])c([R])c3)S3(SC(c4ccc([R])c([R])c4)=C(c4ccc([R])c([R])c4)S3)S2)cc1</smiles>

Figure 4. Molecular structure of the discotic metal-bis(dithiolene) complexes

With only four carbon chains, it was finally demonstrated that all the complexes with $\mathrm{M}=\mathrm{Ni}$, $\mathrm{Pt}, \mathrm{Pd}$ and $\mathrm{n}=1-18$ are deprived of mesomorphic properties. ${ }^{[19]}$ Only the introduction of eight carbon chains at the periphery of the $\left[\mathrm{M}(\mathrm{dphedt})_{2}\right]^{0}$ complex allows for the emergence of liquid crystalline properties. The nickel complexes with eight peripheral alkoxy chains turned out to be mesomorphic. ${ }^{[20]}$ For $n=2-4$, a monotropic phase was detected whereas this phase became enantiotropic for higher chain lengths $(n>5)$ with a slight increase of the monomorphic range 
upon the elongation of the chains. The phase was unambiguously identified by X-ray diffraction to be a $2 \mathrm{D}$ columnar mesophase of hexagonal symmetry $\left(\mathrm{Col}_{h}\right)$. This study was extended to other metal ions $\left(\mathrm{M}=\mathrm{Pd}, \mathrm{Pt} ; \mathrm{R}=\mathrm{R}^{\prime}=\mathrm{OC}_{\mathrm{n}} \mathrm{H}_{2 \mathrm{n}+1}, \mathrm{n}=1-12\right) .{ }^{[21]}$ The same Col $\mathrm{l}_{\mathrm{h}}$ mesophase was observed in the two new series, but appeared at slightly longer chain length $(n=4$ for the Pd complexes, $\mathrm{n}=6$ for the $\mathrm{Pt}$ complexes) and the mesomorphic range decreased as $\mathrm{Pd}>\mathrm{Ni}>\mathrm{Pt}$. For example, with $n=12$, the complex $\left[\mathrm{Ni}(\text { dphedt })_{2}\right]^{0}$ is in a liquid crystalline $\mathrm{Col}_{\mathrm{h}}$ state from 72 to $108{ }^{\circ} \mathrm{C},\left[\mathrm{Pt}(\mathrm{dphedt})_{2}\right]^{0}$ from 62 to $101{ }^{\circ} \mathrm{C}$ and the $\left[\mathrm{Pd}(\mathrm{dphedt})_{2}\right]^{0}$ from 59 to $11{ }^{\circ} \mathrm{C}$.

Furthermore, combined with their electrochemical properties, such discotic mesogens could find potential applications as low-dimensional conductors. Kippelen's research group has measured high electron mobilities around $3 \mathrm{~cm}^{2} \cdot \mathrm{V}^{-1} \cdot \mathrm{s}^{-1}$ in the $\mathrm{Col}_{\mathrm{h}}$ of $\left[\mathrm{Ni}(\mathrm{dphedt})_{2}\right]^{0}$ with $\mathrm{n}=12$ using the space charge limited current (SCLC) characteristics. ${ }^{[22]}$ However, this value seems to be overestimated and a more reasonable value has been measured using the Field Effect Transistor (FET) technique $\left(1.3 \times 10^{-3} \mathrm{~cm}^{2} \cdot \mathrm{V}^{-1} \cdot \mathrm{s}^{-1}\right) .{ }^{[22]}$ Nevertheless, it is apparent that such liquid crystals with a metal-bis(dithiolene) complex as core can be of great interest to obtain films with good conduction properties for applications in organic electronics.

All reported thermotropic dithiolene complexes described so far are neutral nickel, palladium or platinum complexes $\left.[\mathrm{M} \text { (dithiolene })_{2}\right]^{0}$, and accordingly characterized with a low spin $(S=0)$ state. However, gold complexes analogues of the known discotic nickel, palladium or platinum mesogens could afford neutral and radical complexes with a delocalized spin density able to form original magneto-responsive thermotropic phases. In that respect, the synthesis of $\left[\mathrm{Ni}(\mathrm{dphedt})_{2}\right]^{0}$ with $\mathrm{n}=12$ was revisited using $\mathrm{KAuCl}_{4}$ instead of $\mathrm{NiCl}_{2}$ as metal salt. ${ }^{[23]}$ The presence of an unpaired spin on this molecule was confirmed by EPR studies. Combination of polarized light microscopy observations, Differential Scanning Calorimetry (DSC) and small angle X-ray diffraction measurements have shown that this compound form a columnar liquid crystal of hexagonal symmetry from 85 to $117^{\circ} \mathrm{C}$. These values are close to those observed with Nickel, Palladium and Platinum derivatives, which shows that the nature of the metal and the presence of an unpaired spin has little influence on the thermotropic properties (Figure 5). 

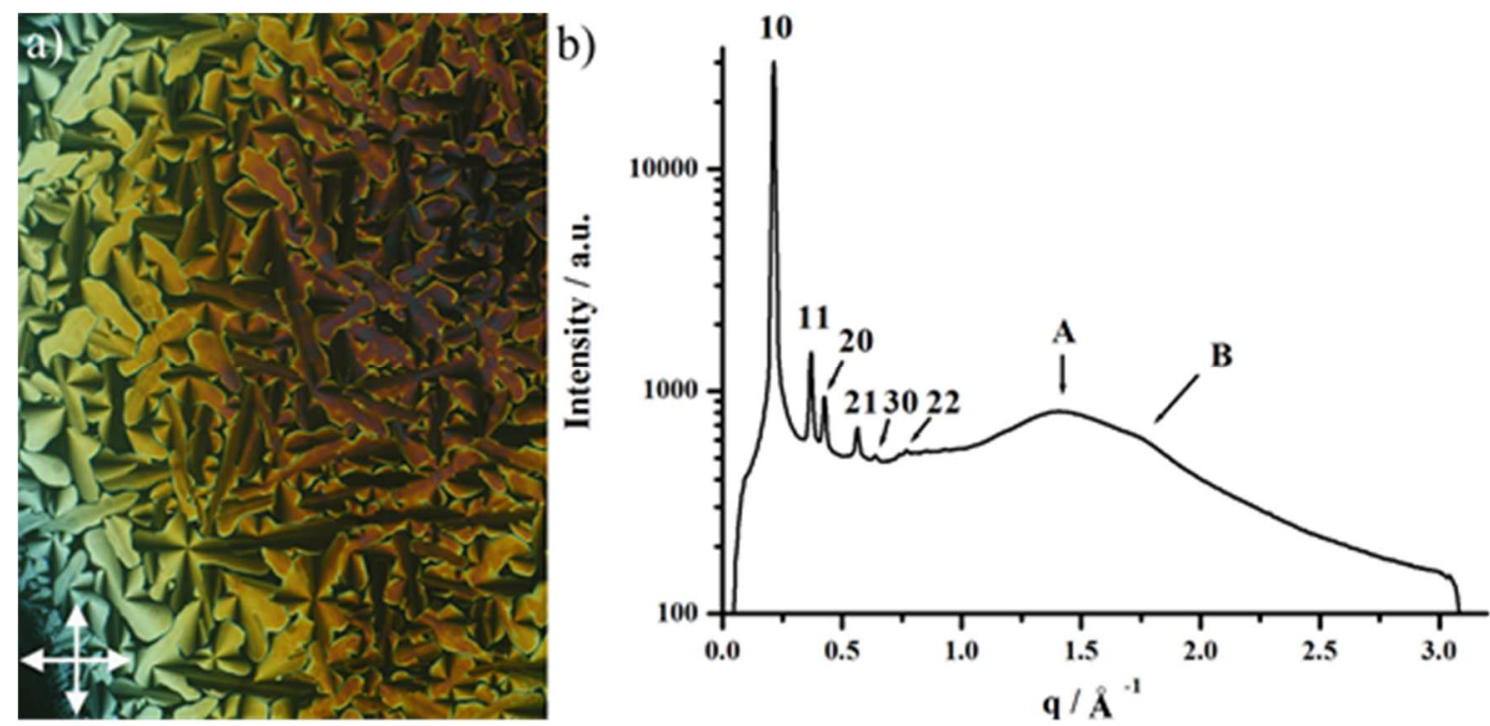

Figure 5. a) Compound $\left[\mathrm{Au}(\mathrm{dphedt})_{2}\right]^{0}$ with $\mathrm{n}=12$ observed by light microscopy polarized at $100{ }^{\circ} \mathrm{C}$ between crossed polarizers (represented by a white cross in the corner of the figure); b) Diffraction pattern of the $\mathrm{Col}_{h}$ phase at $100^{\circ} \mathrm{C}$. Reproduced from ref . ${ }^{[23]}$, Copyright (2011), with permission from The Royal Society of Chemistry.

The magnetic properties of this compound around the crystal / mesophase transition at $85^{\circ} \mathrm{C}$ have also been investigated. At low temperatures, SQUID studies show that in the crystalline state, uniform antiferromagnetic interactions exist between the dithiolene cores along the stacks. Upon heating at the crystal / mesophase transition, a brutal increase of the global magnetic moment is observed. This reflects an increase in the number of free spins during the transition from the crystalline state to the mesophase. The destabilization of the crystalline state is accompanied by a decrease in the number and the range of the antiferromagnetic interactions. After the transition in the mesophase, the magnetic moment reaches a plateau. During cooling, the reverse process is observed and a decrease in overall magnetic moment follows the recovery of antiferromagnetic interactions in the crystalline state. This reversible process reveals a magnetic hysteresis that perfectly matches the thermal behavior of the material around the transition (Figure 6). 


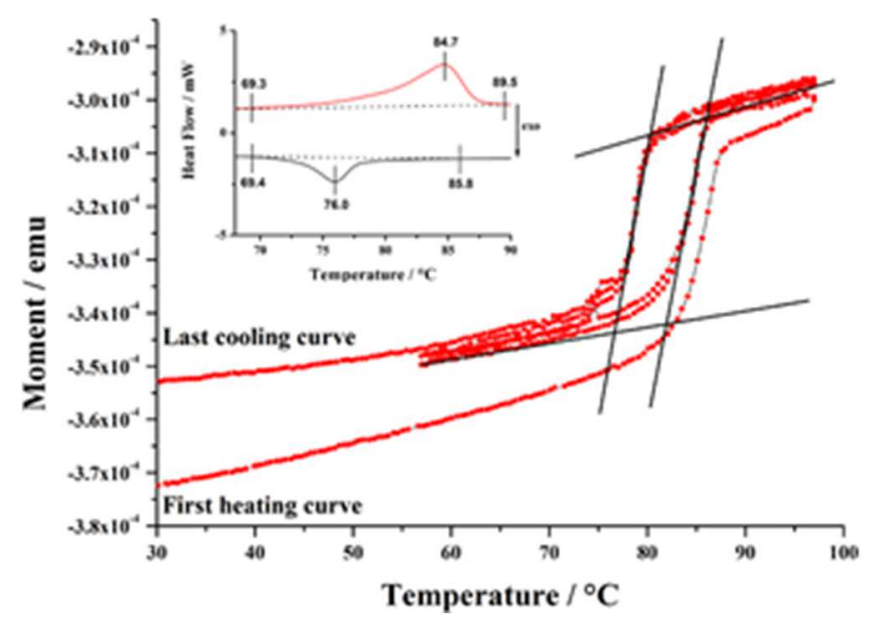

Figure 6. Evolution of global magnetic moment as a function of temperature during heating and cooling cycles around the crystal / mesophase transition at a rate of $10 \mathrm{~K} \cdot \mathrm{min}^{-1}$ (insert: DSC Curves of compound $\left[\mathrm{Au}(\mathrm{dphedt})_{2}\right]^{0}$ with $\mathrm{n}=12$ around the crystal / mesophase transition $\left(2^{\text {nd }}\right.$ heating curve (top) and $1^{\text {st }}$ cooling curve (bottom)). Reproduced from ref. ${ }^{[23]}$, Copyright (2011), with permission from The Royal Society of Chemistry.

This system is one of the rare cases of discotic systems involving radical species. ${ }^{[24]}$ It has also been demonstrated thank to this functional radical dithiolene complex that magnetic interactions between radicals can be modulated markedly in soft matter during phase transitions. It might be interesting to bring to room temperature such magnetic hysteresis to store information. This work demonstrated that, beyond liquid crystalline materials, the used of radical metal-bis (dithiolene) complexes in soft matter can be a good strategy to develop stimuli responsive magnetic materials (vide supra Part 3 on Gels). ${ }^{[25]}$

As mentioned above very few examples of metal-bis(dithiolene) liquid crystals with columnar phases are stable only between 70 and $110^{\circ} \mathrm{C}$. It is interesting to develop new dithiolene-based promotogenic ligands to obtain mesophases at lower temperatures. For this purpose, new benzil derivatives functionalized by two gallate fragments carrying three carbon chains connected by an ester or amide bond have been synthesized. ${ }^{[26]}$ These ligands were efficiently complexed with nickel, allowing to directly introduce twelve carbon chains on the complex (Figure 7). This increase in the density of carbon chains around the metal core should lower the melting points and favour to the emergence of liquid crystal phases at ambient temperature. The ester bond was replaced by an amide bond in the second series of complexes to introduce hydrogen bond donor-acceptor moieties in order to study the influence of hydrogen bond formation on mesophase stability. 

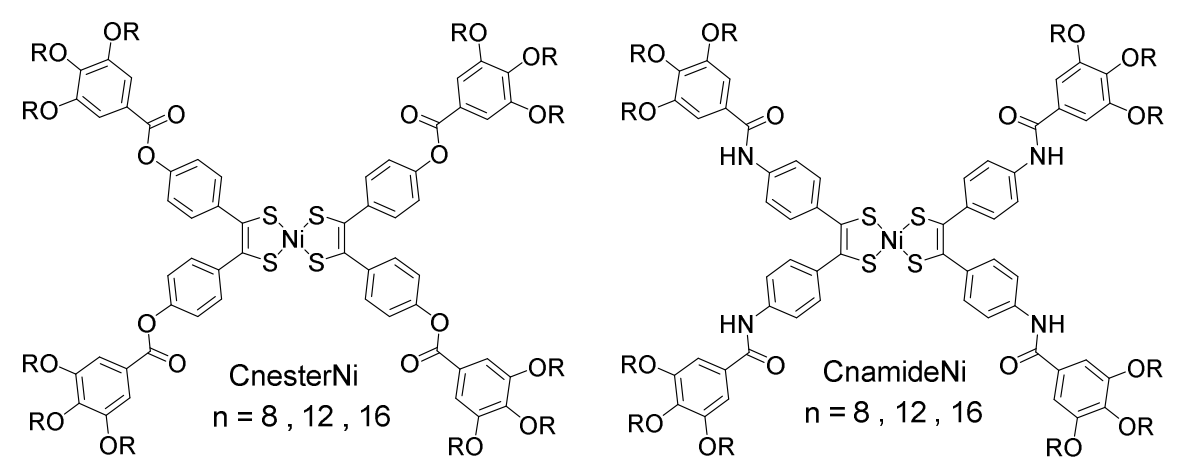

Figure 7. Chemical structure of the nickel-bis(dithiolene) complexes integrating four gallate fragments, each carrying three long carbon chains, connected via ester or amide bonds.

All synthesized complexes show columnar crystal-liquid phases of rectangular or hexagonal symmetry over a wide temperature range including ambient temperature (Table 1).

Table 1. Thermal behaviour of the $C_{n}$ esterNi and $C_{n}$ amideNi compounds $(n=8,12,16)$

\begin{tabular}{|c|c|}
\hline Compound* & Phase and transition temperature in ${ }^{\circ} \mathrm{C}$ \\
\hline $\mathrm{C}_{8}$ esterNi & $\mathrm{Col}_{\mathrm{r}} 89 \mathrm{Col}_{\mathrm{h}} 142$ Iso \\
\hline $\mathrm{C}_{12}$ esterNi & $\mathrm{Cr}-10 \mathrm{Col}_{\mathrm{r}} 90 \mathrm{Col}_{\mathrm{h}} 125$ Iso \\
\hline $\mathrm{C}_{16}$ esterNi & $\mathrm{Cr} 46 \mathrm{Col}_{\mathrm{h}} 82$ Iso \\
\hline $\mathrm{C}_{8}$ amideNi & $\mathrm{Col}_{\mathrm{h}} 155 \mathrm{Cub}^{203 \text { Iso }}$ \\
\hline $\mathrm{C}_{12}$ amideNi & $\mathrm{Cr}-18 \mathrm{Col}_{\mathrm{h}} 177$ Iso \\
\hline $\mathrm{C}_{16}$ amideNi & $\mathrm{Cr} 30 \mathrm{Col}_{\mathrm{h}} 115$ Iso \\
\hline
\end{tabular}

$\mathrm{Col}_{\mathrm{h}}$ : columnar mesophase of hexagonal symmetry; $\mathrm{Col}_{\mathrm{r}}$ : columnar mesophase of rectangular symmetry; Iso : isotropic phase; Cr: crystalline phase; Cub : cubic phase. * See Figure 7.

Introduction of twelve carbon chains strongly reduced the melting temperatures and, stabilized columnar mesophases at room temperature (Table 1). Temperature-dependent infrared spectroscopy studies have also highlighted the role played by donor-acceptor hydrogen bonding groups in the stabilization of the columnar aggregates over wider temperature ranges. ${ }^{[27]}$ This work also showed that mesophases of original symmetry (cubic phase with $\mathrm{C}_{8}$ amideNi) can also be generated.

The isolation of discotic phases at room temperature permits the formation of homogeneous thin films of metal-bis (dithiolene) complexes of good quality. We have therefore turned our interest in the effect of near-infrared laser irradiation on these films. In fact, Nickelbis(dithiolene) are strong near-IR absorbers and they are non-luminescent, implying that all the 
absorbed energy is released in the surrounding as heat. The ability of the Nickel-bis(dithiolene) convert light into heat, i.e. photothermal conversion, was already observed by S. Kawakami and Y. Kojima in 1992 on nickel-bis (dithiolene) thin films and was proposed to develop photothermal layers to transfer images on receiving support under flash exposure. ${ }^{[15]}$ Thus, it can be anticipated that thank to the application of laser radiation it should possible to pass all the phase transitions and to reach the high temperature isotropic liquid phase by photothermal conversion directly. For this, two compounds $\left[\mathrm{Ni}(\mathrm{dphedt})_{2}\right]^{0}$ with $\mathrm{n}=12$ (Figure 4) and C8esterNi (Figure 7) compounds have been selected. These compounds exhibit liquid crystal properties between $70-110^{\circ} \mathrm{C}$ and $25-142^{\circ} \mathrm{C}$, respectively. They form films at room temperature with characteristic textures of columnar phases. The photothermal studies carried out on these films have shown that the application of a laser irradiation allows to easily reach the isotropic phase at 110 or $142{ }^{\circ} \mathrm{C}$ with extremely fast heating kinetics of between 2 and 25 ${ }^{\circ} \mathrm{C} / \mathrm{s}$ depending on the laser power density used. Such heating rates cannot be achieved with conventional hot plate systems. These studies also showed that the complexes are highly stable under laser irradiation and no fatigue of the system was observed after several cycles of heating/irradiation and cooling. Closer look at the films using polarized light microscopy at room temperature before laser irradiation showed that $\left[\mathrm{Ni}(\mathrm{dphedt})_{2}\right]^{0}$ with $\mathrm{n}=12$ films has a strong tendency to form large homeotropic domains in which the columns are aligned perpendicular to the glass surfaces. Upon laser irradiation, the film can locally be melted into the isotropic state and that the extent of the melted surface directly depends on the intensity of the laser used. Interestingly, after stopping the laser irradiation, the film cooled very quickly generating locally an optical texture that is very different from the rest of the film. Indeed, the fast cooling does not leave time for the molecules to reorganize properly in the homeotropic phase and a texture consisting of a multitude of birefringent microdomains is then generated. By a conventional heat treatment, it is then possible to regenerate the homeotropic phase and then to rewrite by the application of a new laser irradiation (Figure 8). This writing and erasing process can be performed several times and in a very reproducible manner. These studies show that the photothermal properties of metal-bis (dithiolene) complex films can therefore be exploited to store information ${ }^{[28]}$ but can also be of interest to develop sensors or artificial muscles (vide supra). 


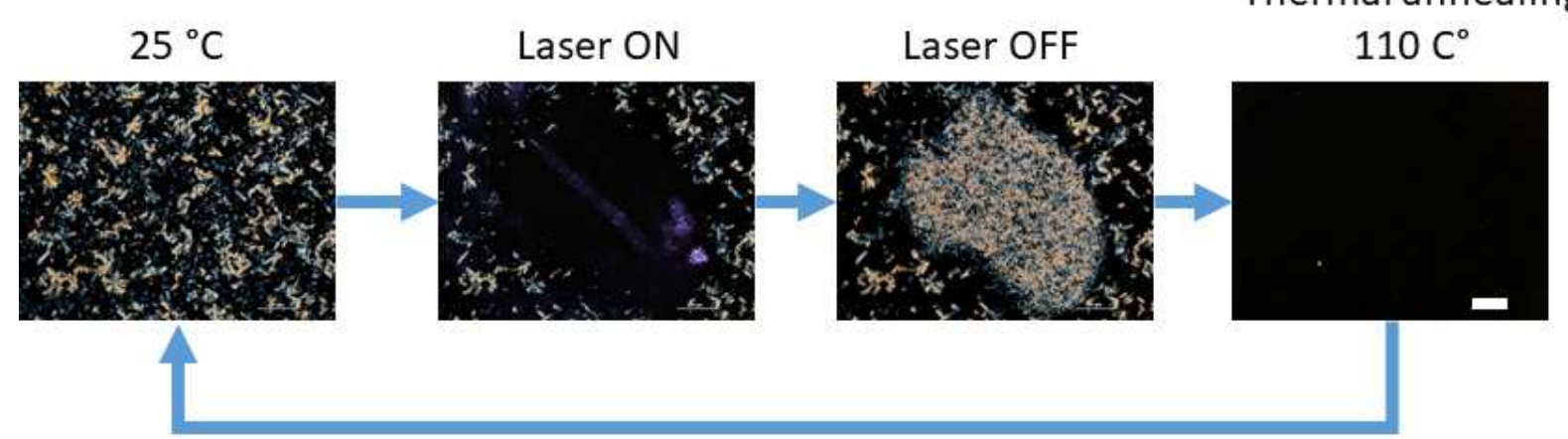

Cooling

Figure 8. Polarized light microscopy images showing the reversibility of the writing and erasing process obtained on a metal-bis (dithiolene) complex film under laser irradiation. Adapted from ref. ${ }^{[28]}$, Copyright (2017), with permission from The Royal Society of Chemistry.

In our quest to develop new metal-bis (dithiolene) mesogens, we turned our attention on the grafting of long carbon chains around another interesting metal-bis(dithiolene) complexes, i.e. nickel (II) N,N'-dialkylimidazolidine-2,4,5-trithione complexes $\left(\left[\mathrm{Ni}\left(\mathrm{R}_{2} \text { timdt }\right)_{2}\right]\right) .{ }^{[29]}$ For this purpose, a new synthetic route starting from commercial and / or easily accessible ionic liquids was developed (Figure 9a). UV-vis-NIR absorption studies have confirmed that these complexes strongly absorb in the near infrared around $1000 \mathrm{~nm}$ with molar extinction coefficients of the order of $80000 \mathrm{M}^{-1} \cdot \mathrm{cm}^{-1}$, among the highest measured for metalbis(dithiolene) complexes. It has also been demonstrated that these complexes can efficiently convert near-infrared radiation into heat with conversion efficiencies around 30\% (Figure 9b). The mesomorphic properties of these complexes have been investigated by a combination a DSC measurements, Polarized Optical Microscopy (POM) observations and X-Ray Diffraction (XRD). Unfortunately, none of the seven $\left[\mathrm{Ni}\left(\mathrm{R}_{2} \mathrm{timdt}\right)_{2}\right]$ complexes functionalized by linear or branched chains $\left(\mathrm{R}=\mathrm{n}-\mathrm{C}_{4} \mathrm{H}_{9}, \mathrm{n}-\mathrm{C}_{8} \mathrm{H}_{17}, \mathrm{n}-\mathrm{C}_{12} \mathrm{H}_{25}, \mathrm{n}-\mathrm{C}_{16} \mathrm{H}_{33}\right.$, 2-ethylhexyl, 2-butyloctyl, phytanyl) shows liquid crystalline properties and only crystalline or amorphous phases have been detected. However, these nickel $\mathrm{R}_{2}$ timdt complexes are, by their accessibility, their ease of functionalization, their photo and thermal stability and their photothermal conversion efficiency, good candidates to develop new photothermal agents. 

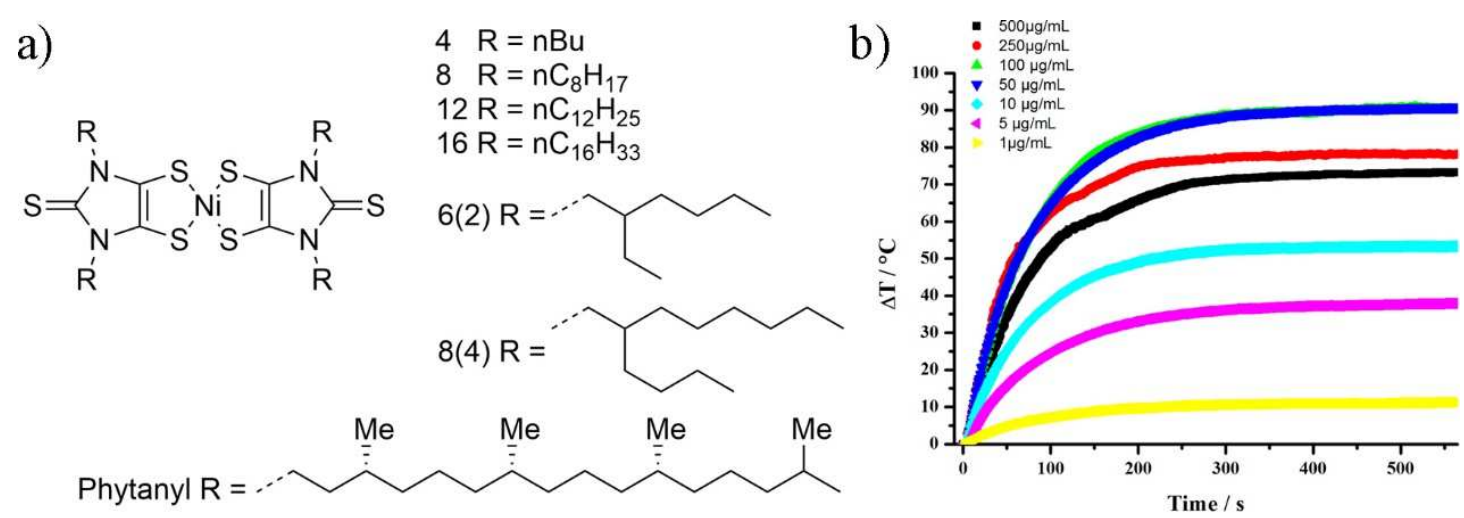

Figure 9. a) N,N'-dialkylimidazolidine-2,4,5-trithione nickel (II) complexes ([Ni(R2timdt)2]) functionalized by linear or branched chains $\left(\mathrm{R}=\mathrm{n}-\mathrm{C}_{4} \mathrm{H}_{9}, \mathrm{n}-\mathrm{C}_{8} \mathrm{H}_{17}, \mathrm{n}-\mathrm{C}_{12} \mathrm{H}_{25}, \mathrm{n}-\mathrm{C}_{16} \mathrm{H}_{33}, 2-\right.$ ethylhexyl, 2-butyloctyl, phytanyl) developed; b) Temperature increases of solutions of $6(2)$ complex in toluene at different concentrations $\left(0-500 \mu \mathrm{g} \cdot \mathrm{mL}^{-1}\right)$ measured as a function of time (0-600 s) under irradiation at $940 \mathrm{~nm}$ with a power of $5 \mathrm{~W} \cdot \mathrm{cm}^{-2}$. Adapted from ref ${ }^{[29]}$, Copyright (2016), with permission from the American Chemical Society.

Despite the absence of mesomorphic properties of ([Ni( $\left.\left.\left.\mathrm{R}_{2} \mathrm{timdt}\right)_{2}\right]\right)$ series, their good photothermal properties were exploited to develop efficient photo-responsive actuators of great interest, for example, in soft robotic. Soft robotic is an emerging branch of robotic developing soft materials able to mimic the environmental responsiveness of living organisms such as the leaf closure of carnivorous plants, the twisting of plant tendrils, the winding of the tentacles of an octopus ... ${ }^{[30]}$ Soft robots offer new possibilities to tack problems that cannot be addressed by robots built from rigid bodies. ${ }^{[31]}$ Bio-inspired by these natural features, scientists develop soft actuator materials to transform external stimuli (such as electricity, light, heat, and chemical energy) into mechanical motion. Photoresponsive polymer actuators are especially attractive since light allows for remote and localized actuation of the polymers without the need to connect tubes or wires. ${ }^{[32]}$ Thus, soft liquid crystalline polymer film which can be stimulated with light are particularly appealing.

Along these lines, the ([Ni( $\mathrm{R}_{2}$ timdt $\left.\left.)_{2}\right]\right)$ complex functionalized by 2-butyloctyl carbon chains (8(4) complex) was physically entrapped into an elastomer constructed from biphenyl unit and photopolymerizable cinnamyl moieties for cross-linking (Figure 10a and b). ${ }^{[33]}$ Absorption of the complex is slightly blue-shifted to $974 \mathrm{~nm}$ in the photopolymerized film (Figure 10b). Film temperature increases of up to $90^{\circ} \mathrm{C}$ are measured under laser irradiation (Figure 10c) with only $0.2 \%$ by weight of metal-bis (dithiolene) complex introduced. This shows that a very small amount of complex is sufficient to reach under irradiation the crystal-liquid/isotropic transition. 
Thanks to a strategy of asymmetric polymerization between the two sides of a film of this doped polymer (polycrystalline layer on one side and monocrystalline layer on the other), it is possible to modify the curvature of the polymer film under NIR laser irradiation $(\lambda=980 \mathrm{~nm})$ (Figure 10d).

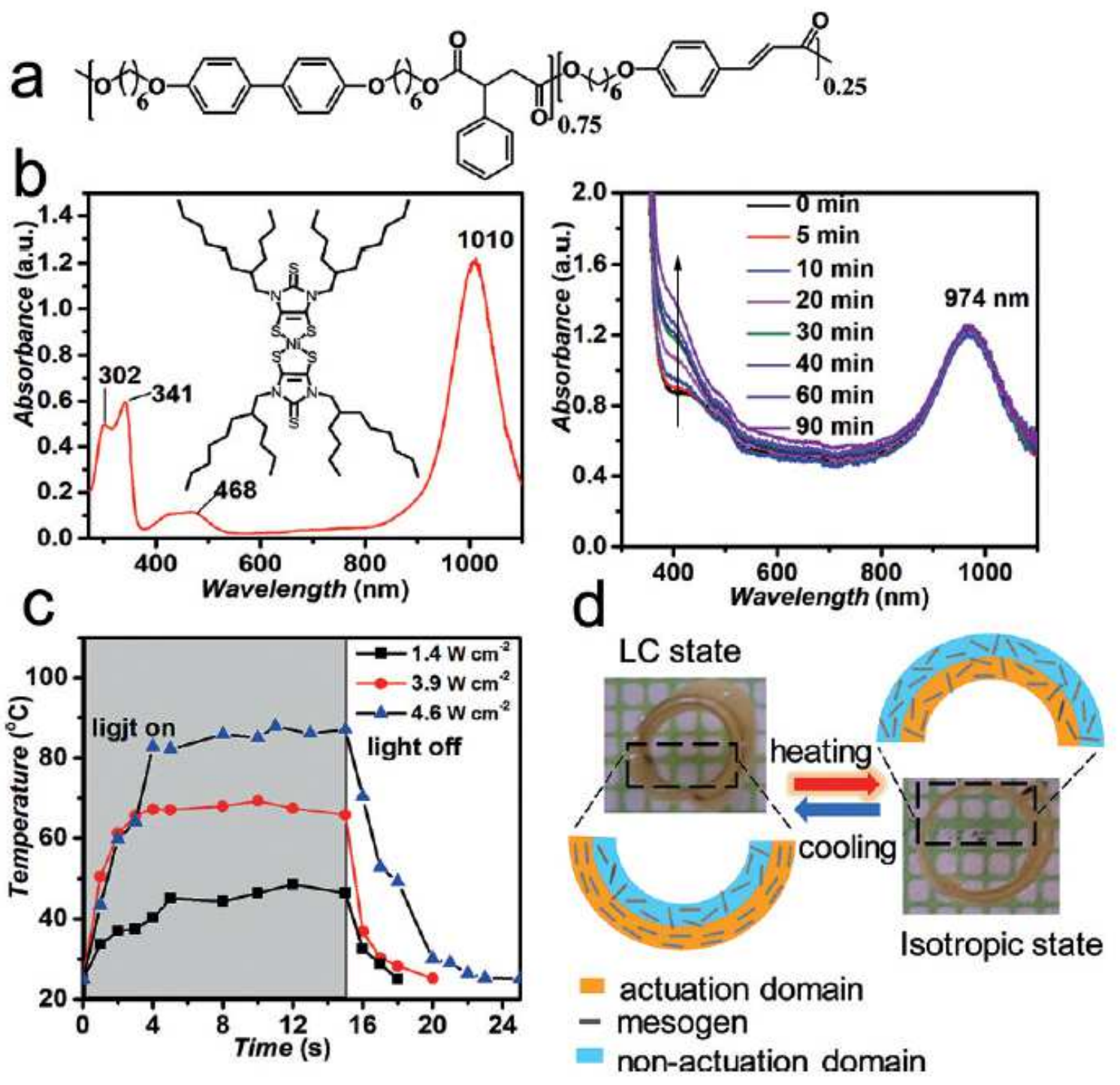

Figure 10. a) Chemical structure of the liquid crystal elastomer (LCE) used; b) Structure of the metal-bis(dithiolene) complex used as photothermal agent (8(4) complex), (left) UV-Vis-NIR absorption spectrum of this complex in dichloromethane, and (right) absorption spectra of the LCE film with $0.2 \% \mathrm{w} / \mathrm{w}$ imNi8(4) before and after UV irradiation $\left(160 \mathrm{~mW} . \mathrm{cm}^{-2}\right)$ for photocrosslinking; c) Temperature variation of the LCE/8(4) film irradiated at $980 \mathrm{~nm}$ at different intensities with on/off times; d) Reversible curling for the asymmetric film between the nematic phase and the isotropic phase. Reproduced from ref. ${ }^{[33]}$, Copyright (2018), with permission from WILEY-VCH Verlag GmbH \& Co. 
Now, if the two ends of a strip of this polymer are fixed on a surface, under laser irradiation, a bump is generated at the initial laser spot and scanning the ribbon at the foot of the bump with the laser, allows to move this bump along the strip from one side to the other in both directions (monocrystalline layer to the surface) (Figure 11). After, if a round object like a carbon bar is placed in front of this bump, it is possible to move this bar over the entire length of the strip by scanning it with the laser. The large-amplitude bump movement observed is likely explained by the use of the extra length of the strip from the initial bump by the new bump formed nearby the laser spot upon scanning. This doped liquid-crystalline polymer, exploiting the photothermal properties of the nickel-bis(dithiolene) complex, has here first allowed to develop a conveyor which is activated by light.

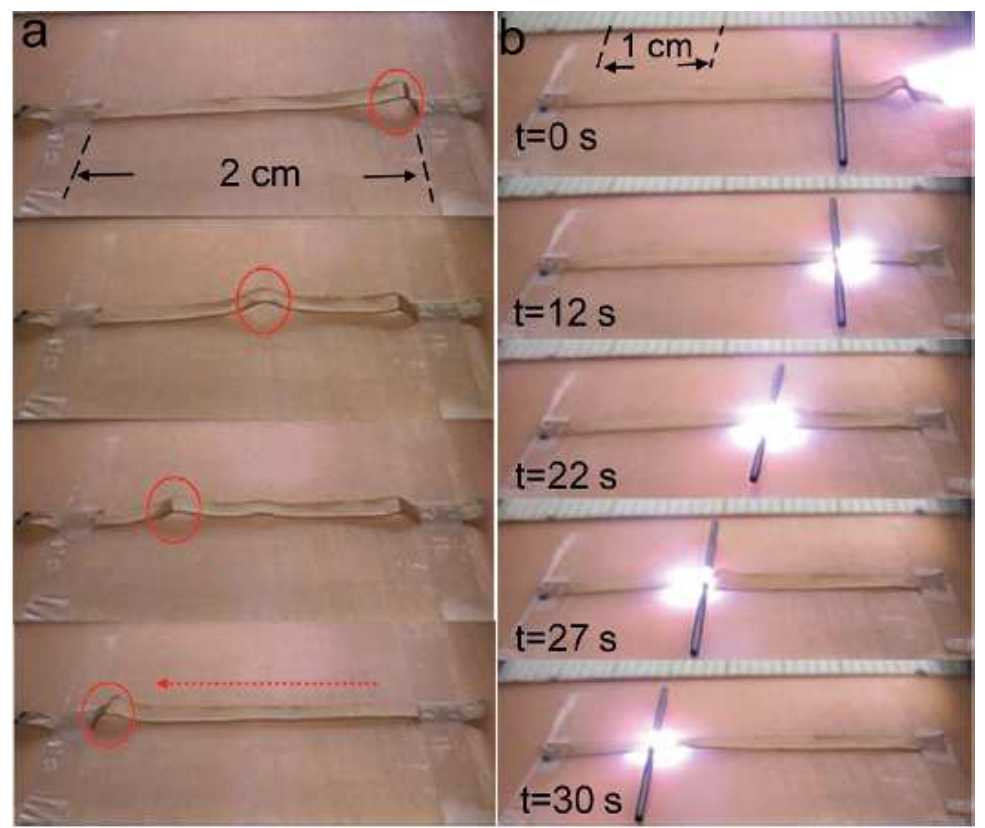

Figure 11. a) Photographs showing the generation and movement of a bump on a strip of LCE/8(4) upon $980 \mathrm{~nm}$ laser scanning. b) Photographs showing laser-driven transportation of a carbon bar pushed by the bump along the actuator strip. Reproduced from ref. ${ }^{[33]}$, Copyright (2018), with permission from WILEY-VCH Verlag GmbH \& Co.

Now, let's take a piece of this bump with the two ends unattached on the surface and the actuating side of the strip setting downward. When this polymer fragment is scanned with the laser from the "head" to the "tail", elevation and folding of the tail is observed while the head remains on the surface. When the laser leaves the tail, the body descends, sticks on the surface and elongates, causing the head to move forward (Figure 12a). The repetition of this procedure makes it possible to move forward the piece of polymer on the surface such as a caterpillar. It 
was shown that this piece of polymer was able to move straight on a flat surface or on an inclined plane $\left(15^{\circ}\right)$ but also that it was also able to turn to the right or to the left by scanning diagonally the piece of polymer with the laser (Figure 12b, $\mathrm{c}$ and d).
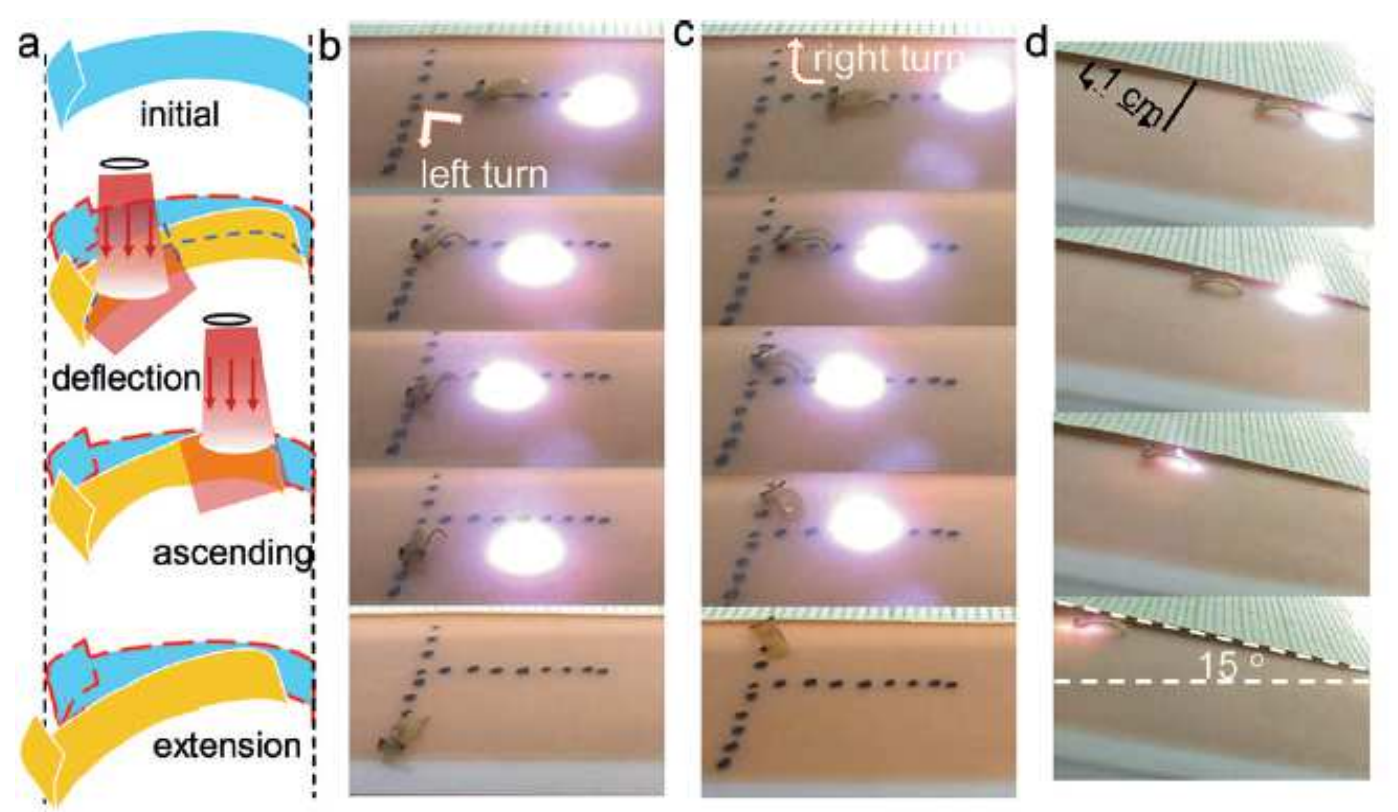

Figure 12. a) Illustration of the crawler moving process under laser irradiation. b) and c) Photographs showing a left turn and a right turn at right angle using an asymmetric laser scanning; d) Photographs showing climbing on an inclined surface at $15^{\circ}$. Reproduced from ref. ${ }^{[33]}$, Copyright (2018), with permission from WILEY-VCH Verlag GmbH \& Co.

Finally, one end of an actuator strip was attached (with the actuation downside) to the substrate surface, leaving the other end suspending in air. (Figure 13). Under a fixed laser irradiation at the suspended end, an upward bending is first observed (melting of the polycrystalline layer) and then a strong downward bending appears (melting of the monocrystalline layer). When folded downward, the piece of polymer leaves the laser irradiation, allowing the polymer to cool and to return to its original position. The polymer is then irradiated again and the movement is repeated. Under fixed and continuous irradiation, a perpetual motion is generated like that of an arm that rises and falls (Figure 13a). If irradiation is done with an angle, a twisting motion can also be induced (Figure 13b). 


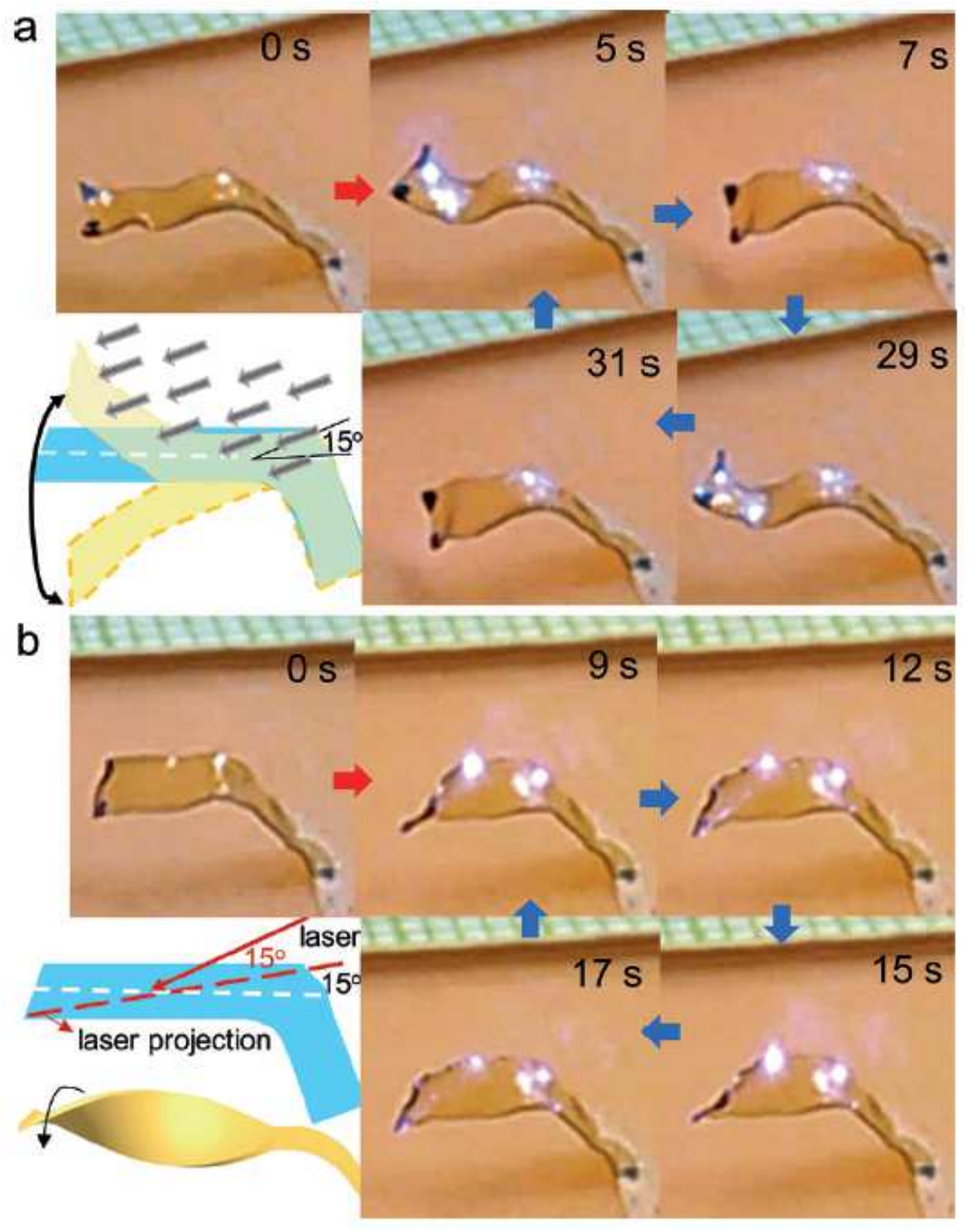

Figure 13. a) Autonomous arm-like motions of the actuator strip laser: applied at an angle of $15^{\circ}$ along the ribbon; b) Autonomous twisting: laser applied at a grazing angle of $15^{\circ}$ and shifted by $15^{\circ}$ with respect to the long axis of the ribbon. Reproduced from ref. ${ }^{[33]}$, Copyright (2018), with permission from WILEY-VCH Verlag GmbH \& Co.

In conclusion, the doping of an elastomer with a metal-bis(dithiolene) complex, coupled with an asymmetrical film polymerization strategy, has allowed to obtain a multifunctional material combining different abilities. Indeed, a material capable under light irradiation to move objects, to generate an autonomous and perpetual movement or to walk / move on surfaces has been developed, which represents a significant advance in the field of soft robotics.

Liquid crystalline heteroleptic coordination complexes can also be generated with functional ligands. In fact, platinum diimine-dithiolene complexes displaying liquid crystalline properties have been isolated using functional bipyridines. The first liquid crystalline material build around a metal diimine-dithiolene core has been described by Ho-Chol Chang and coworkers in 2011 (Figure 14a). ${ }^{[34]}$ A platinum complex having an asymmetric molecular 
structure derived from 1,2-benzenedithiolato (bdt) and a bipyridine ligand carrying ramified C13(8) carbon chains forms a columnar mesophase of hexagonal symmetry over a large temperature range from $-18{ }^{\circ} \mathrm{C}$ up to $194{ }^{\circ} \mathrm{C}$. More recently, new liquid crystalline material build around a metal diimine-dithiolene core have been isolated by an original ligand metathesis synthetic route using bipyridine fragments carrying either tris-dodecyloxyphenyl fragments connected through an amide linker (bpyC12) or cyanobiphenyl fragments connected through ester linker carrying a C10 carbon chain (bpyCBP) (Figure 14b, c, d and e). ${ }^{[35]}$ After coordination to $\mathrm{PtCl}_{2}$, the chlorine ligands have been successfully exchanged by 5,6-dihydro1,4-dithiin-2,3-dithiolato (dddt) or 1,2-bis(3,4-bis(dodecyloxy)phenyl)ethene-1,2-bis(thiolato) (C12dt) dithiolene ligands directly from preformed tin or nickel dithiolene complexes. DSC and temperature-dependent X-ray analyses have revealed that, with the bpyC12 diimine ligand, columnar mesophase can be obtained over large temperature ranges, showing that this ligand is a good mesogenic promoter. On the contrary, with the bpyCBP diimine ligand, it was mandatory to introduce numerous long carbon chains on the dithiolene fragment to observe the emergence of liquid crystalline properties. The ambipolar character of these compounds was revealed by electrochemical investigation coupled to DFT calculations. In fact, the liquid crystalline platinum diimine-dithiolene complexes can reversibly be oxidized and reduced at easily accessible potentials. In particular, the platinum compound with the dddt and the bpyC12 ligands can clearly be reversibly oxidized or reduced and self-assembles into a lamellocolumnar phase over a large temperature range from $42{ }^{\circ} \mathrm{C}$ up to $180{ }^{\circ} \mathrm{C}$. Such ambipolar and liquid crystalline platinum diimine-dithiolene complexes are promising candidates to develop new semiconducting soft materials. 
a)<smiles></smiles>
Cr $18 \mathrm{Col}_{\mathrm{h}} 194$ Iso

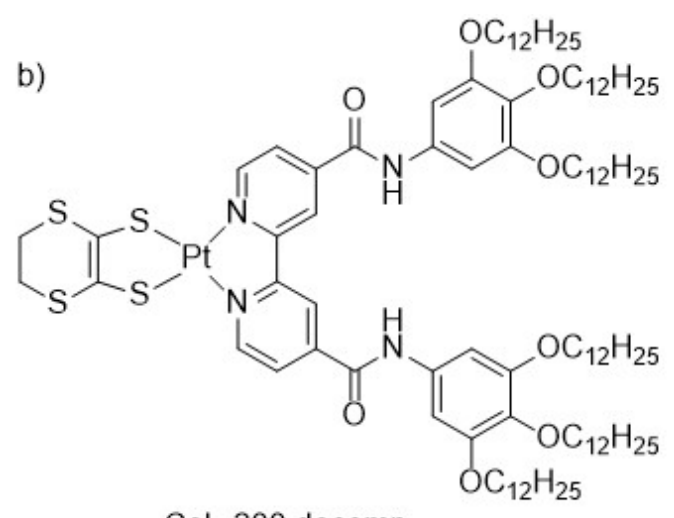

$\mathrm{Col}_{\mathrm{h}} 200$ decomp c)

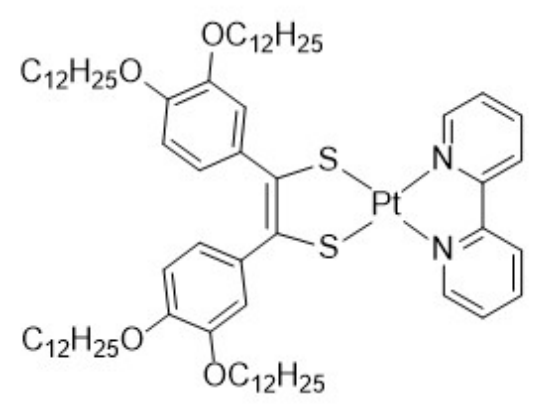

Cr 42.5 Lam $_{\text {col }} 180$ decomp d)

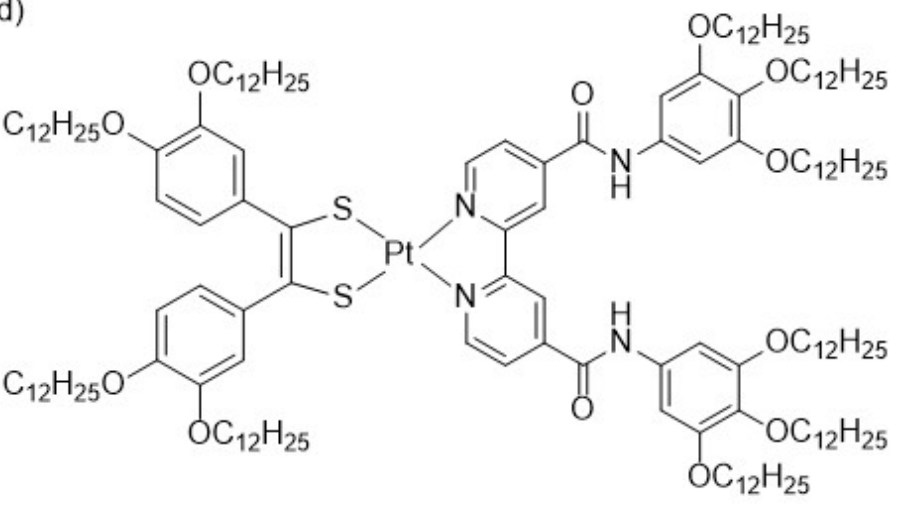

$\mathrm{Cr}-14 \mathrm{Col}_{\mathrm{h}} 120$ Iso

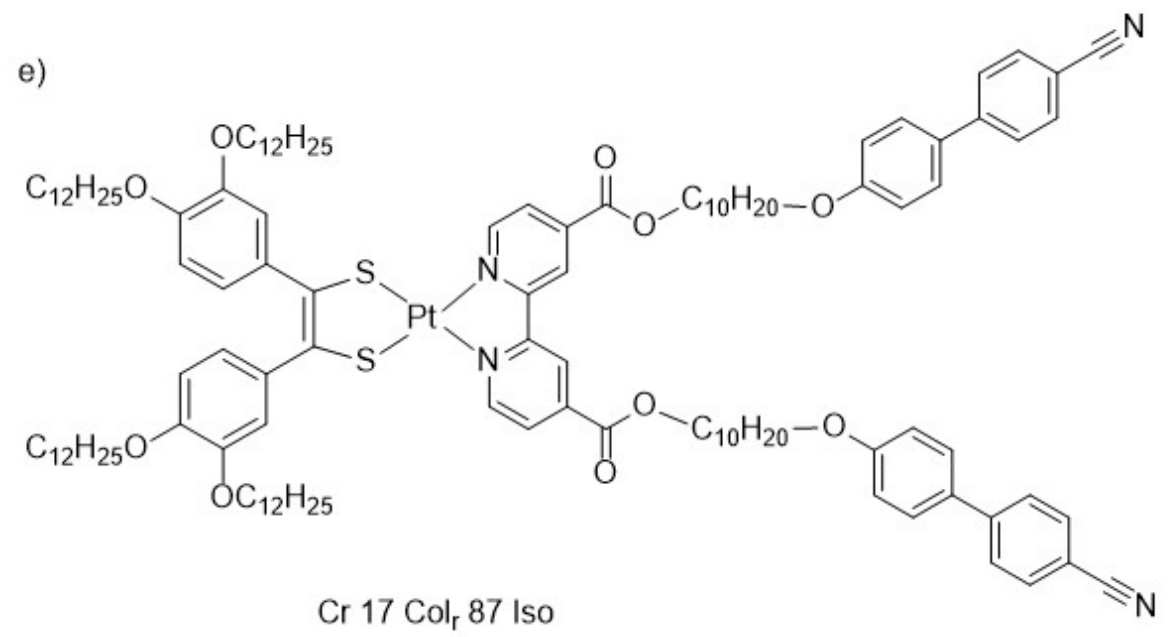

Figure 14. Chemical structure of the liquid crystalline diimine-dithiolene complexes reported with their thermal behaviors (a: (bdt)Pt(bpyC13(8)); b: (dddt)Pt(bpyC $\left.\mathrm{C}_{12}\right)$; c: $\left(\mathrm{C}_{12} \mathrm{dt}\right) \mathrm{Pt}(\mathrm{bpy})$; d: $\left(\mathrm{C}_{12} \mathrm{dt}\right) \mathrm{Pt}\left(\mathrm{bpyC}_{12}\right)$; e: $\left.\left(\mathrm{C}_{12} \mathrm{dt}\right) \mathrm{Pt}(\mathrm{bpyCBP})\right)\left(\mathrm{Col}_{\mathrm{h}}\right.$ : columnar mesophase of hexagonal symmetry; Colr: columnar mesophase of rectangular symmetry; Iso: isotropic phase; Cr: crystalline phase; Decomp : decomposition)

Liquid crystalline metal-bis(dithiolene) and metal-diimine dithiolene complexes can be obtained from functional dithiolene ligands. Their molecular organization can easily be disturbed with the temperature, useful to modulate the extended of electronic intermolecular interactions such as magnetic interactions. Metal-bis(dithiolene) complexes also display 
remarkable photothermal properties which can also be used to disturb molecular organizations under laser irradiation. This peculiar property combined to the ease of functionalization of metal-bis(dithiolene) complexes offers numerous possibilities to develop light-responsive materials of great interest for optical data storage and soft-robotic.

\section{Gels}

Low molecular weight gelators (LMWGs) or organogelators are small molecules able to selfassemble in solution into extended supramolecular structures such as fibers or layers which by spatial interactions or interconnections lead to the immobilization of the solvent. ${ }^{[36]}$ The formation of physical supramolecular gels from LMWGs is an attractive and elegant way to organize molecules at the nano- and microscale level into stimuli responsive soft materials. To induce self-assembly in solution into flexible nanostructures, LMWGs are usually constructed from rigid aromatic parts, hydrogen bonded motifs and flexible carbon chains. The stacking of the molecules in solution is favored by the $\pi-\pi$ interactions between the aromatics parts and intermolecular hydrogen bonding interactions. The directionality of these two types of interactions usually lead to the formation of 1D nanostructures. Long carbon chains or steroid fragments are also grafted in order to import flexibility and micro-segregation properties in solution as well as additional van der Waals interactions. Some common architectures are presented in Figure 15. The presence of hydrogen bonding donor is not mandatory but usually favor the emergence of the gel state, reinforce the intermolecular interactions and improve the mechanical properties. Systems incorporating metal center, also called metallogelators, are of particular interest since the presence of the metal allow to import new properties such as luminescence, conductivity, catalytic activity, magnetism... to the gels. ${ }^{[37]}$ Several systems based on metal coordination with polymers or functional ligands have been developed but there is a need to design of new metallogelators in order to develop new stimuli responsive gels for tailored applications in biosciences, molecular electronics, sensing, or as confined reaction media and templates for inorganic materials. 


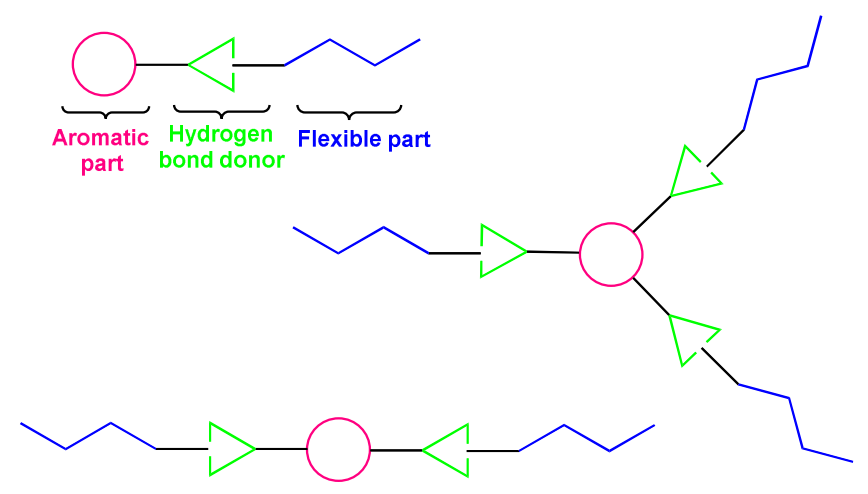

Figure 15. Typical construction schemes of low molecular weight gelators.

Despite the absence of hydrogen bond donor fragments, the gelation properties of the paramagnetic $(\mathrm{S}=1 / 2)$ neutral gold complex $\left[\mathrm{Au}(\mathrm{dphedt})_{2}\right]^{0}$ with $\mathrm{n}=12$ have been evaluated. ${ }^{[23]}$ This compound was found to be able to form brittle gels in linear alkanes (C6-C12) (Figure 16a). Scanning electron microscopy (SEM) studies showed that the formation of a network of entangled fibers is responsible for the immobilization of the solvent (Figure 16b). SQUID studies were also performed on these gels around the gel/sol transition. The solubilization/fragmentation of fibers at the gel/sol transition is accompanied by an increase in the number of free spins and therefore a rapid increase in the global magnetic moment, demonstrating that the study of the magnetic interactions as a function of the temperature can also be used to probe aggregation processes within gels.

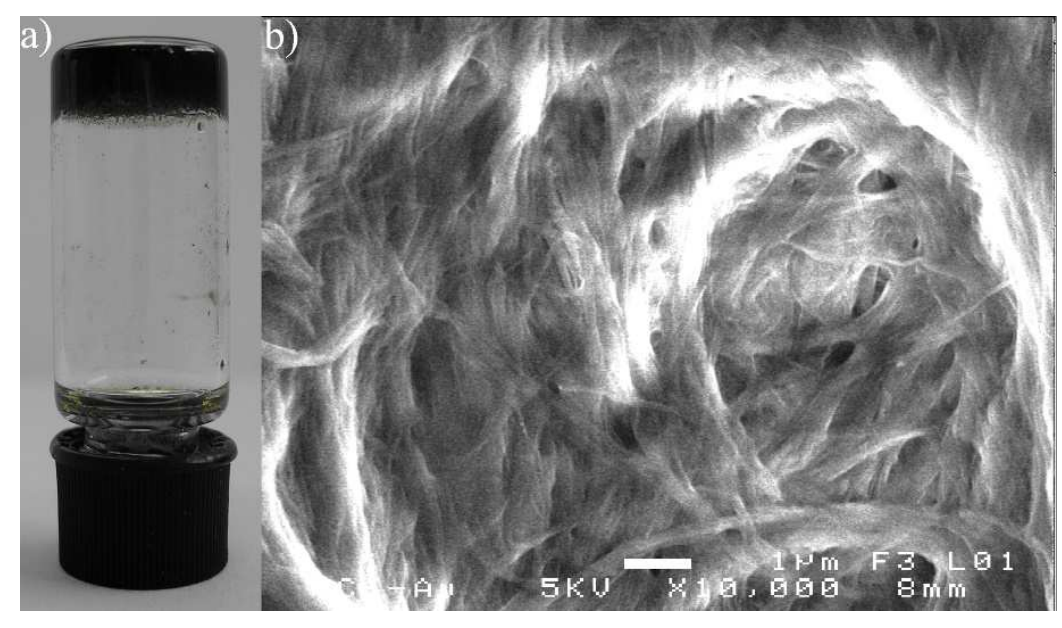

Figure 16. a) Dark green gel obtained in dodecane ( $\left.23 \mathrm{mmol} . \mathrm{L}^{-1}\right)$; b) SEM image of an aerogel of compound $\left[\mathrm{Au}(\mathrm{dphedt})_{2}\right]^{0}$ with $\mathrm{n}=12$ in hexane $\left(23 \mathrm{mmol} . \mathrm{L}^{-1}\right)$ deposited on a silicon wafer showing the interconnected network of fibers. Reproduced from ref. ${ }^{[23]}$, Copyright (2011), with permission from The Royal Society of Chemistry. 
These gelators integrating a central $\left[\mathrm{Au}(\mathrm{dphedt})_{2}\right]^{0}$ complex were the first reported metallogelators using a metal-bis(dithiolene) complex. However, the obtained gels displayed poor mechanical properties and large quantities of gelator were needed to obtain gels. To improve the gelation ability of metal-bis(dithiolene) complexes and the mechanical properties of the obtained gels, four cholesteryl fragments have been grafted at the periphery of the nickelbis(dithiolene) complexes (Figure 17) ${ }^{[38]}$ Cholesteryl fragments are known to be able, when grafted on functional molecules, to produce gels and especially chiral gels. ${ }^{[36,39]}$ Chiral gels, induced by the helical winding of the elementary fibrils, can generate chiro-optical effects which can easily modulated with the temperature. The gelation properties of the $\mathrm{Ni}_{4} \mathrm{C}_{\mathrm{n}}$ complexes with $n=2,6,11$ have been evaluated in different polar, apolar, protic and non-protic solvents. These complexes are very soluble in chlorinated solvents such as dichloromethane or chloroform as well as in dioxane and THF. The $\mathrm{Ni}_{4} \mathrm{C}_{2}$ and $\mathrm{Ni}_{4} \mathrm{C}_{6}$ complexes were found to be good gelators of linear alkanes for C7 to $\mathrm{C} 12$ as well as cyclohexane (Figure 18b). The gels obtained are robust, transparent and stable for several months and have reversible sol/gel transitions.<smiles>[R]c1ccc(-c2sc3c(-c4ccc([R])c([R])c4)s[nH]n-3sc2-c2ccc([R])c([R])c2)cc1[R]</smiles>

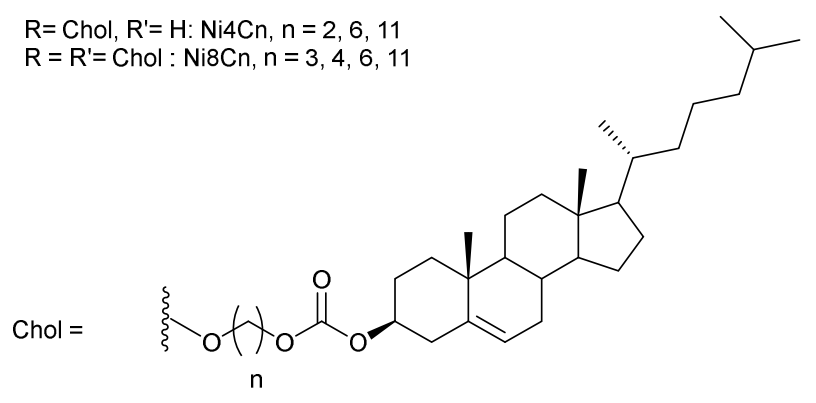

Figure 17. Structure of the nickel-bis(dithiolene) complexes with 4 cholesteryl fragments $\operatorname{Ni} 4 \mathrm{Cn}(\mathrm{n}=2,6,11)$ and with 8 cholesteryl fragments Ni8Cn $(\mathrm{n}=3,4,6,11)$.

Scanning electron microscopy (SEM) show that the immobilization of the solvent is induced by the formation of a dense network of twisted fibers. These fibers have an average diameter 
of $\sim 100 \mathrm{~nm}$ and are several micrometers long (Figure 18a). The fiber width is large compared to the dimensions of the molecule. So, these fibers are certainly formed by molecular assemblies of smaller size. To confirm this observation, atomic force microscopy (AFM) studies was performed. The obtained images show smaller sized fibers with a mean diameter of $12 \mathrm{~nm}$, which can be considered as being formed by a single stack of complexes based on the dimension determined on a Dreiding model (Figure 18c). Closer look also shows that these fibers are striated and this patterning probably stems from a helical arrangement of the complexes into right-handed $(\mathrm{P})$ helices.

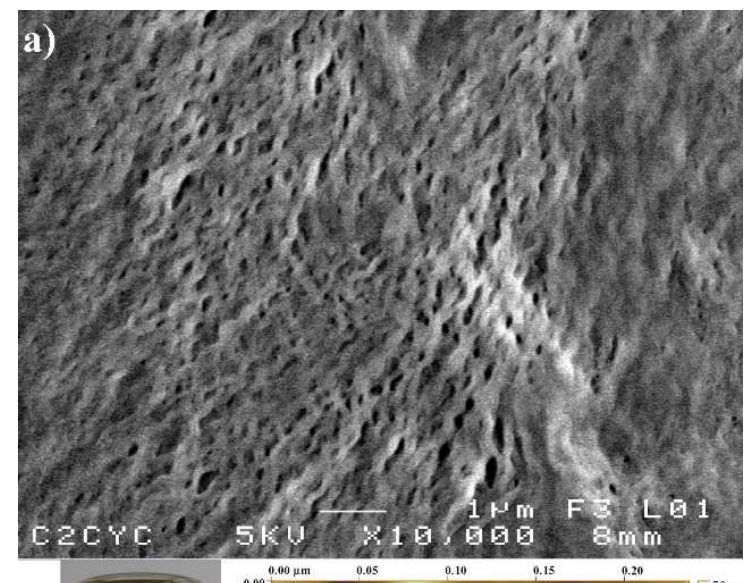

b)

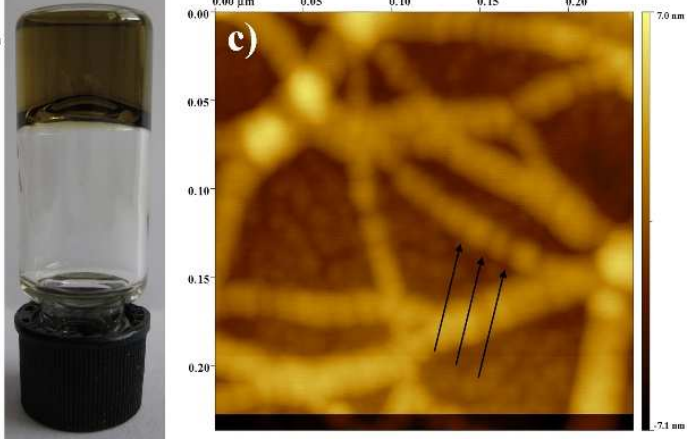

Figure 18. a) SEM image of an aerogel of $\mathrm{Ni}_{4} \mathrm{C}_{2}$ in cyclohexane $(\mathrm{C}=2 \mathrm{mg} / \mathrm{mL})$; b) Gel of $\mathrm{Ni}_{4} \mathrm{C}_{2}$ obtained in dodecane $(0.7 \mathrm{mg} / \mathrm{mL})$; c) AFM image $(0.25 \mu \mathrm{m} \times 0.25 \mu \mathrm{m})$ of a diluted gel of $\mathrm{Ni}_{4} \mathrm{C}_{2}$ in cyclohexane $(\mathrm{C}=0.2 \mathrm{mg} / \mathrm{L})$ deposited on HOPG. Adapted from ref. ${ }^{[38]}$, Copyright (2012), with permission from The Royal Society of Chemistry.

To confirm the formation of right-handed helices, circular dichroism studies were undertaken on these gels. A strong dichroic effect is observed in the UV but also more remarkably also in the NIR region, which confirms that the gels formed are indeed chiral (Figure 19a). The strong dichroic signal with a positive Cotton effect positive at $945 \mathrm{~nm}$ and negative one at $826 \mathrm{~nm}$ in the NIR is characteristic of a right-handed helix and confirms the AFM observations. Note that circular dichroism measurements performed in chloroform, in which the complexes are soluble, do not show any dichroic effect. Therefore, the self-assembly of these complexes in solution 
into straight right handed helices clearly appears to be at the origin of the strong dichroic effects observed, in particular, in the NIR. The increase of the temperature, which induces a progressive disaggregation process, leads indeed to a continuous decrease of the CD signal (Figure 19b). Upon cooling, the gel is formed and the CD signal is restored. The CD signal can thus be turned on or off reversibly at the gel/sol transition by simply changing the temperature.
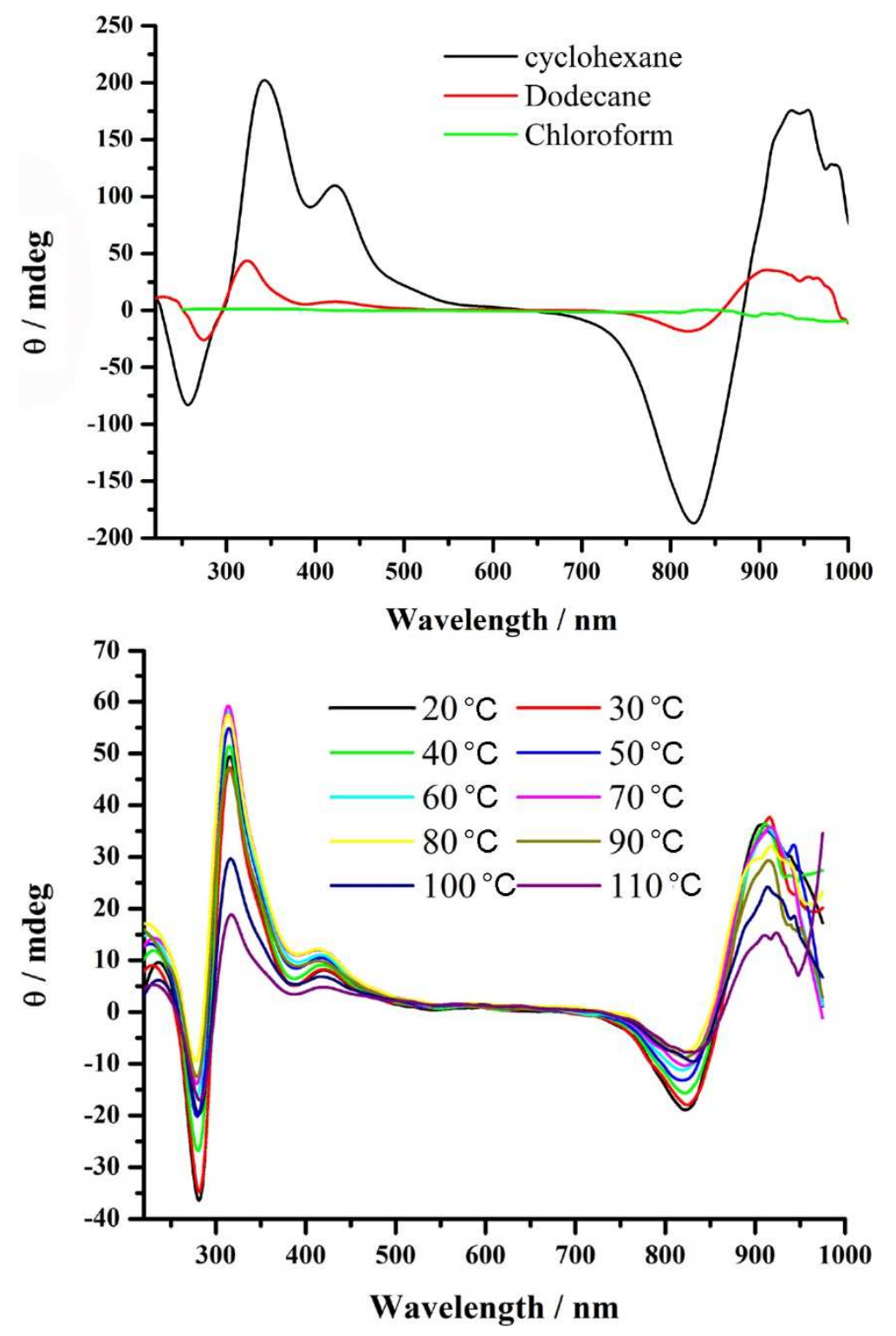

Figure 19. a) $\mathrm{CD}$ spectra of $\mathrm{Ni}_{4} \mathrm{C}_{2}$ in chloroform $(\mathrm{C}=0.6 \mathrm{mg} / \mathrm{mL})$ solution and in cyclohexane $(\mathrm{C}=1 \mathrm{mg} / \mathrm{mL})$ and dodecane $(\mathrm{C}=0.5 \mathrm{mg} / \mathrm{mL})$ diluted gels; b) Temperature-dependent $\mathrm{CD}$ signal of $\mathrm{Ni}_{4} \mathrm{C}_{2} /$ dodecane diluted gel $(\mathrm{C}=0.5 \mathrm{mg} / \mathrm{mL})$. Adapted from ref. ${ }^{[38]}$, Copyright (2012), with permission from The Royal Society of Chemistry.

This work has been extended to the introduction of eight cholesteryl fragments around the metal-bis(dithiolene) core, again using different link lengths between the cholesteryl moiety 
and the dithiolene ligand (Figure 15). ${ }^{[40]}$ The gelation properties of the $\mathrm{Ni} 8 \mathrm{C}_{\mathrm{n}}$ complexes with $\mathrm{n}=3,4,6,11$ have been evaluated in various solvents and gels have been obtained in linear alkanes with $\mathrm{Ni}_{8} \mathrm{C}_{4}$ and $\mathrm{Ni}_{6} \mathrm{C}_{6}$ complexes. However, these complexes were found to be less effective obtaining strong gels and the minimum gelation concentrations are much higher than with Ni4Cn complexes. This was attributed to a larger steric hindrance around the complex.

Nevertheless, in this work, the photothermal property of the nickel-bis (dithiolene) core has efficiently been exploited to control the gelation properties. The photothermal efficiency of these $\mathrm{Ni} 8 \mathrm{C}_{\mathrm{n}}$ complexes was first evaluated in solution in decane under laser irradiation in the NIR. These complexes have good photoconversion properties in decane (around $19 \%$ efficiency) and a temperature increase of $50^{\circ} \mathrm{C}$ can be achieved in less than 10 min under a laser power of $1 \mathrm{~W}$ and a concentration of $10 \mathrm{mg} \cdot \mathrm{mL}^{-1}$. The effect of the laser irradiation in the NIR has then been investigated directly on the gels. Figure 20 shows that under laser irradiation, the gel begins to flow at the point of impact on the front of the vial after 1-2 min irradiation and, upon longer exposure time, the penetration of the laser and the diffusion of heat resulted in a complete destructuration of the gel. After $5 \mathrm{mi}$, the gel is completely decomposed upon laser irradiation, due to the aforementioned photothermal properties of the nickelbis(dithiolene) complex. This is the first example in which the photothermal agent is at the same time the gelator. The kinetics of this degelation process depends, of course, on the concentration of gelator and on the power of the laser used. After stopping the laser and cooling of the solution, the gel is reformed. This experiment shows that the photothermal properties of metalbis(dithiolene) complexes can be used to tune the gelation properties. Such photoactivatable gels under laser irradiation offer new perspectives for nanotechnology applications.

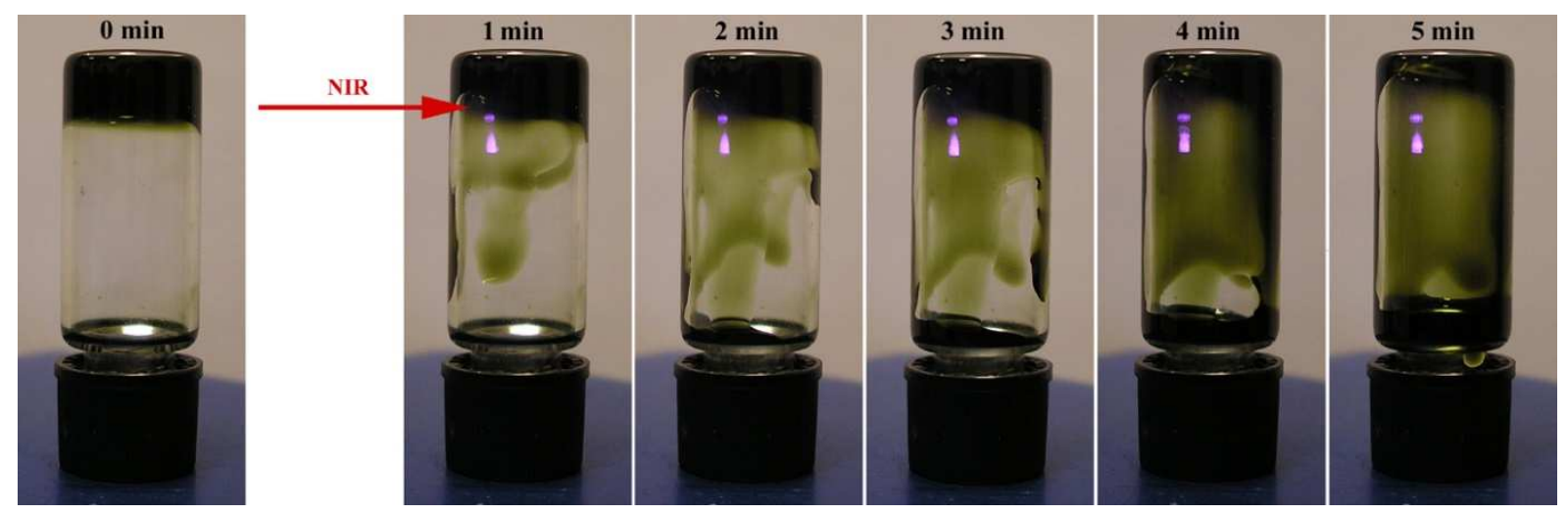

Figure 20. Evolution over time of a gel of $\mathrm{Ni}_{8} \mathrm{C}_{6} /$ Dodecane $(72 \mathrm{mg} / \mathrm{mL})$ under laser irradiation at $980 \mathrm{~nm}$ (diameter $7 \mathrm{~mm}, 960 \mathrm{~mW} \cdot \mathrm{cm}^{-2}$ ). Adapted from ref ${ }^{[40]}$, Copyright (2014), with permission from the American Chemical Society.. 
These works demonstrated that metal-bis(dithiolene) complexes can be functionalized to produce effective gelation agents. Gel formation allows to organize these complexes into anisotropic supramolecular structures that could be of interest for applications in optoelectronics. It has also been demonstrated that the absorption properties in the near infrared can be modulated by the generated self-assemblies but also that the absorption properties, i.e the photothermal effect, can be used to destabilize the stability of the supramolecular edifice. Since these species are also electroactive, it would be interesting to see if the molecular organizations in the gel state could be stimulated by electric field. It would also be interesting to extend these researches to other metals such as gold.

\section{Nanoparticules}

Numerous applications have been develop by exploiting the photothermal effect. As mentioned previously, photothermal effect has been used to develop photo-responsive materials such as liquid crystals, gels and polymers. ${ }^{[41]}$ Photothermal polymer films have also been used to develop some water purification systems, with evaporation/condensation processes, working with sun light. ${ }^{[42]}$ Photothermal agents have also found a strong interest in biotechnologies for applications in photothermal therapy and in photo-controlled drug delivery as well as for bioimaging. ${ }^{[43]}$ Many organic ${ }^{[44]}$ or inorganic ${ }^{[45]}$ photothermal agents have been reported but there is still a need to find photothermal moieties with good photothermal properties, high stability, good clearance and low toxicity to develop new efficient therapeutic agents. As already demonstrated, metal-bis(dithiolene) complexes display good photothermal properties with conversion efficiency reaching up to $40-50 \%$ and are highly stable under laser irradiation. However, for applications in a biological medium, it is necessary to obtain water-soluble complexes with low toxicity.

For this purpose, a first series of metal-bis(dithiolene) complexes functionalized with polyethylene glycol chains was synthesized (Figure 21). ${ }^{[46]}$ Polyethylene glycol chains have been selected for their good water solubility and their biocompatibility. Solubility tests and spectroscopic studies carried out on these complexes have shown that it is necessary to introduce at least 8 triethylene glycol chains around the metal-bis(dithiolene) core in order to obtain good solubility in water (Complex 3 in Figure 21). 


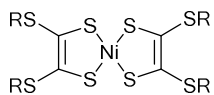
5. $\mathrm{COY}_{3}$

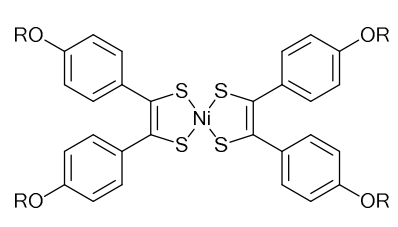

2

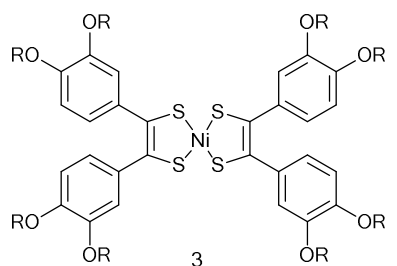

Figure 21. Chemical structure of the pegylated nickel-bis(dithiolene) complexes synthesized.

Photothermal studies of complex $\mathbf{3}$ have shown that this complex has a photothermal activity in water with a conversion efficiency of near infrared light energy in heat around $12 \%$. This system is competitive with gold nanorods which are currently intensively studied in thermal phototherapy and which have efficiencies around $15-20 \%$ in the near infrared region. ${ }^{[47]}$ The good photothermal efficiency in the near infrared of these complexes in water led to the evaluation of the photothermal potential of these complexes in cellulo experiments. Tetrazolium salt (MTT) tests carried out on 786-0 human renal carcinoma cells showed that the viability remained greater than $80 \%$ after 24 hours of incubation at concentrations as high as $100 \mu \mathrm{g} \cdot \mathrm{mL}^{-1}(60 \mu \mathrm{M})$. The cells were then incubated with increasing amounts of complexes $\left(50,100,150 \mu \mathrm{g} \cdot \mathrm{mL}^{-1}\right)$ for $24 \mathrm{~h}$ and then irradiated with a $940 \mathrm{~nm}$ near-infrared laser for $10 \mathrm{~min}$ with a power of 2 or $5 \mathrm{~W} . \mathrm{cm}^{-2}$. Under irradiation at $5 \mathrm{~W} . \mathrm{cm}^{-2}$, the cell viability decreases drastically for complex concentrations greater than $100 \mu \mathrm{g} \cdot \mathrm{mL}^{-1}$ (Figure 22) and after $10 \mathrm{~min}$ less than $20 \%$ of the cells survived. Control tests carried out show that the presence of complex is necessary to induce a significant cell death under IR irradiation.

These preliminary results show that the proper functionalization of the metalbis(dithiolene) complexes make it possible to obtain photothermal agents that are effective in a biological medium. To decrease the toxicity of these complexes, one possible strategy is their encapsulation into soft biocompatible nanoparticles such as polymer nanoparticles or liposomes made from lipids. The stability of organic nanoparticles integrating such metal-bis(dithiolene) complexes should highly sensitive to laser irradiation due to the heat increase induced by the photothermal effect and such soft nanoparticles should be useful to develop remote-controlled drug delivery systems. 


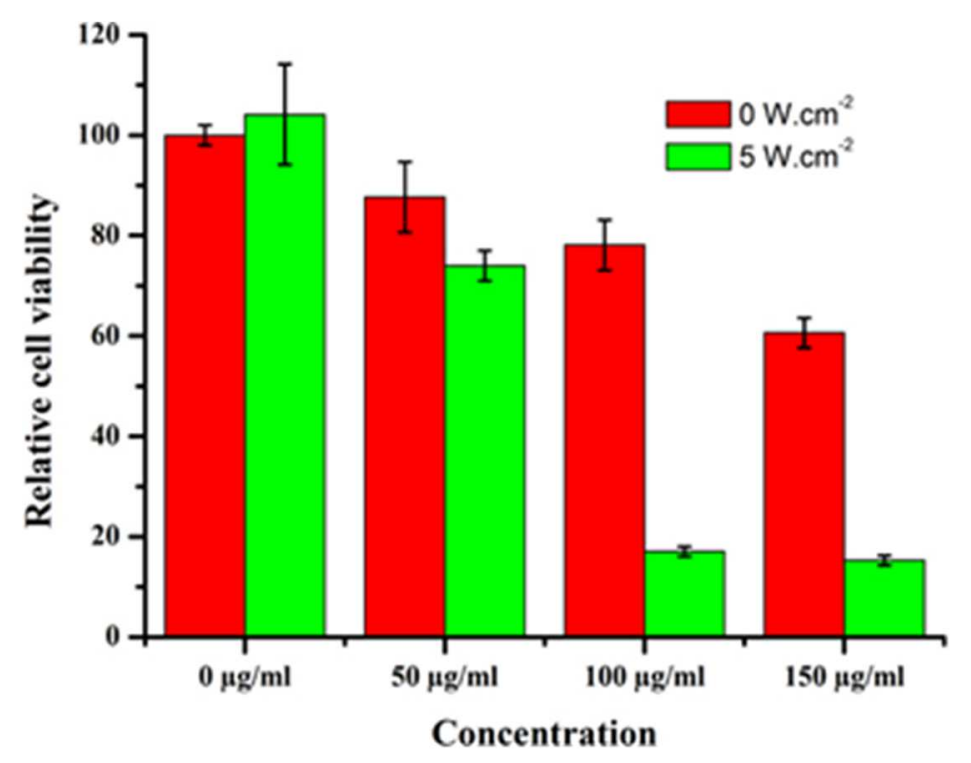

Figure 22. Relative Cell viability 786-0 human renal carcinoma cells treated with different concentrations of complex 3 without or with laser irradiation $\left(940 \mathrm{~nm}, 5 \mathrm{~W} . \mathrm{cm}^{-2}, 10 \mathrm{~min}\right)$. Reproduced from ref. ${ }^{[46]}$, Copyright (2015), with permission from The Royal Society of Chemistry.

Along these lines, a hydrophobic nickel-bis(dithiolene) complex $\left[\mathrm{M}(\mathrm{dphedt})_{2}\right]^{0}$ bearing four $\mathrm{OC}_{12} \mathrm{H}_{25}$ fragments was encapsulated within PEG-b-PMLABe type block copolymer nanoparticles using the nanoprecipitation technique. ${ }^{[48]}$ The poly(malic acid), PMLA, and its derivatives is an attractive polymer to develop (bio)degradable and biocompatible block copolymers-based nanocarriers. ${ }^{[49]}$ Encapsulation rates were determined and nanoparticle sizes were determined by Dynamic Light Scattering (DLS) and transmission electron microscopy (Figure 23a). The hydrophobic complex was introduced at a maximum of $13 \%$ by weight in the core of polymeric nanoparticles which reach a size of $110 \mathrm{~nm}$. Studies under laser irradiation have shown that these nanoparticles are able to efficiently convert light energy into heat and that they remain stable and effective after several irradiation cycles (Figure 23b). An anticancer drug, Doxorubicin, has also been co-encapsulated and studies under laser irradiation have shown that the active agent can be released in a controlled manner either by applying a long laser irradiation or by using pulses of laser irradiation. In cellulo studies have revealed that the introduction of metal-bis(dithiolene) complexes within these polymer nanoparticles does not increase their toxicity and that under laser irradiation, these nanoparticles can induce strong cell death by photothermal effect (Figure 23c). These nanoparticles containing metal-bis(dithiolene) complexes are therefore good candidates for photothermal therapy and photo-controlled drug delivery under laser irradiation. 

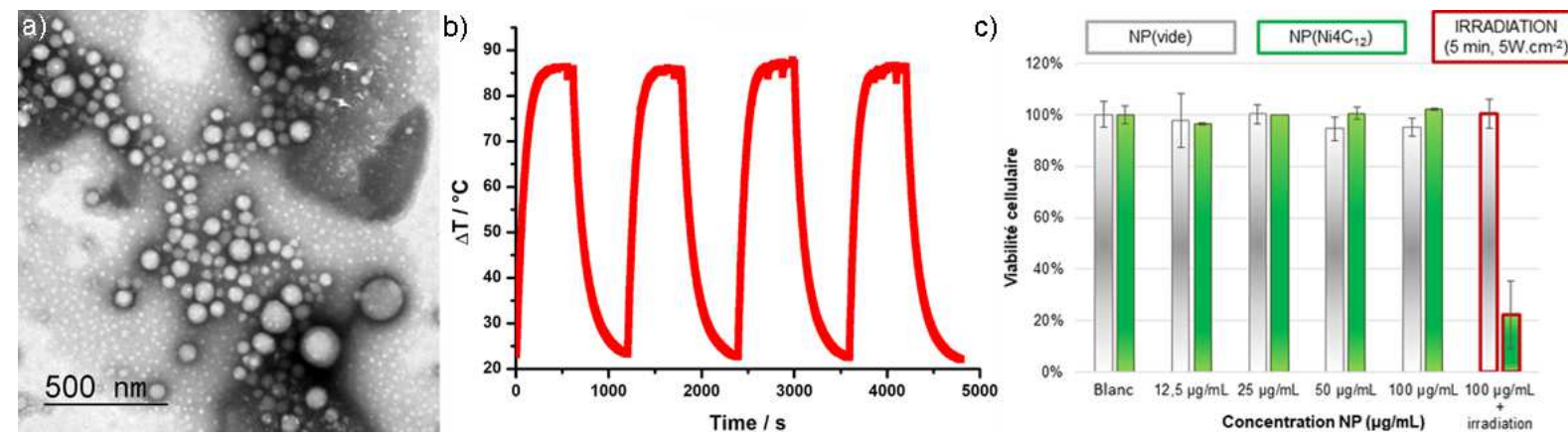

Figure 23. a) TEM image of the polymer nanoparticles containing $10 \%$ by weight of metalbis(dithiolene) complex; b) Laser irradiation cycles; c) In cellulo studies without and with irradiation at $940 \mathrm{~nm}$ (5 min). Adapted from ref. ${ }^{[48]}$, Copyright (2018), with permission from The Royal Society of Chemistry.

Metal-bis (dithiolene) complexes have also been introduced into liposomes. Hydrophobic $\left[\mathrm{M}(\mathrm{dphedt})_{2}\right]^{0}$ dithiolene complexes carrying eight $\mathrm{C} 12$ chains were encapsulated in the lipid bilayer liposomes of EggPC-PEG2000-DSPE (Lp) liposomes while hydrophilic ones carrying eight triethylene glycol chains were encapsulated (Complex 3 in Figure 21) in the liposome core ${ }^{[50]}$ A maximum of $5 \%$ by weight of the hydrophobic complex was introduced into the lipid wall of liposomes with an average size of $180 \mathrm{~nm}$. On the other hand, $13 \%$ by weight of the hydrophilic complex could be introduced into the aqueous core of liposomes with a mean size of $90 \mathrm{~nm}$.

Size studies by DLS over the time have shown that these nanoparticles doped with nickelbis(dithiolene) complexes are stable for several months. The photothermal activities of the nanoparticles containing the metal-bis(dithiolene) complexes have also been quantified. Photothermal studies, in addition to confirming high photothermal activity and good thermal and photochemical stability of the complexes, have shown that these complexes do not produce singlet oxygen under irradiation in the near infrared which is important to preserve the integrity of the active drug that can be co-encapsulated.

Fluorophores and drugs were then encapsulated within these liposomes containing metalbis(dithiolene) complexes. The photothermal properties of the complexes allow to modulate the physicochemical properties of the nanocapsules and to release active species under irradiation in the NIR (Figure 24). By varying the irradiation times and the power of the laser used, it is possible to control the amount of active species released. The release can be done either quickly or gradually. This type of nanoparticles offers new possibilities for high spatial and temporal 
control of the drug delivery under laser irradiation, while the introduction of metalbis(dithiolene) complexes does not increase the toxicity of the liposomes.

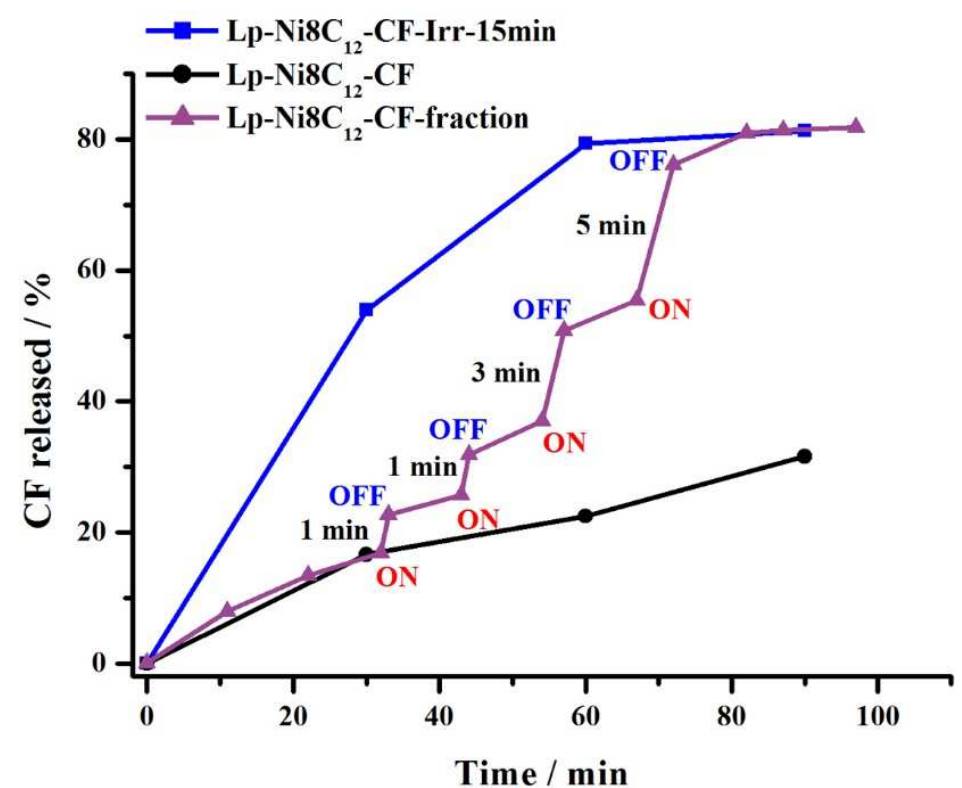

Figure 24. Percentage of 6-carboxyfluorescein (CF) released from photothermosensitive liposomes containing metal-bis(dithiolene) complexes with or without laser irradiation (940 $\mathrm{nm}, 5 \mathrm{~W} . \mathrm{cm}^{-2}$ ) at different time intervals. Reproduced from ref. ${ }^{[50]}$, Copyright (2017), with permission from WILEY-VCH Verlag GmbH \& Co.

Toxicological data on metal-bis(dithiolene) complexes are very limited and the pharmacokinetic of these complexes still have to be evaluated. The only information available is that the IC50 of a nickel-bis(dithiolene) complex carrying eight triethyleneglycol chains is around $500 \mu \mathrm{g} / \mathrm{mL} .{ }^{[46]}$ The IC50 of nickel-bis(dithiolene) complex carrying long carbon chains could not have been determined due to their strong hydrophobicity. However, cytotoxicity experiments clearly show that the trapping of an hydrophobic nickel-bis(dithiolene) complex inside liposomes or polymer nanoparticles does not import any additional toxicity to the organic nanocarriers. ${ }^{[48][50]}$

More recently, new liposomal formulation integrating $\left[\mathrm{M}(\mathrm{dphedt})_{2}\right]^{0}$ metalbis(dithiolene) complexes carrying eight $\mathrm{C} 12$ chains, displaying a thermal phase transition at $42{ }^{\circ} \mathrm{C}$, have been developed by a judicious mixing of dipalmitoylphosphatidylcholine (DPPC), distearoylphosphatidylcholine (DSPC), lyso-phosphatidylcholine (LPC) and [poly(ethylene glycol)-2000]-amine,1,2-distearoyl-sn-glycero-3-phosphoethanolamine (PEG2000-DSPE). The mild hyperthermia generated under NIR laser irradiation at $940 \mathrm{~nm}$ by nickelbis(dithiolene) complexes allows for the fine controlled release of the liposome contents 
whereas these liposomes are highly stable and keep their contents at $37{ }^{\circ} \mathrm{C}$ for several days. Moreover, it has been demonstrated, here again, that the hyperthermia generated by the complex inside the liposome under NIR irradiation exhibits a high potential for photothermal therapy. More importantly, it has been demonstrated that metal-bis(dithiolene) complexes display good photoacoustic properties. The photoacoustic signal coming from the nickel-bis(dithiolene) complex is easily detected and its intensity is directly proportional to the concentration of complex and to the laser energy (Figure 25). These last results show that this class of complexes can also be used as exogenous contrast agents for photoacoustic bioimaging. ${ }^{[51]}$

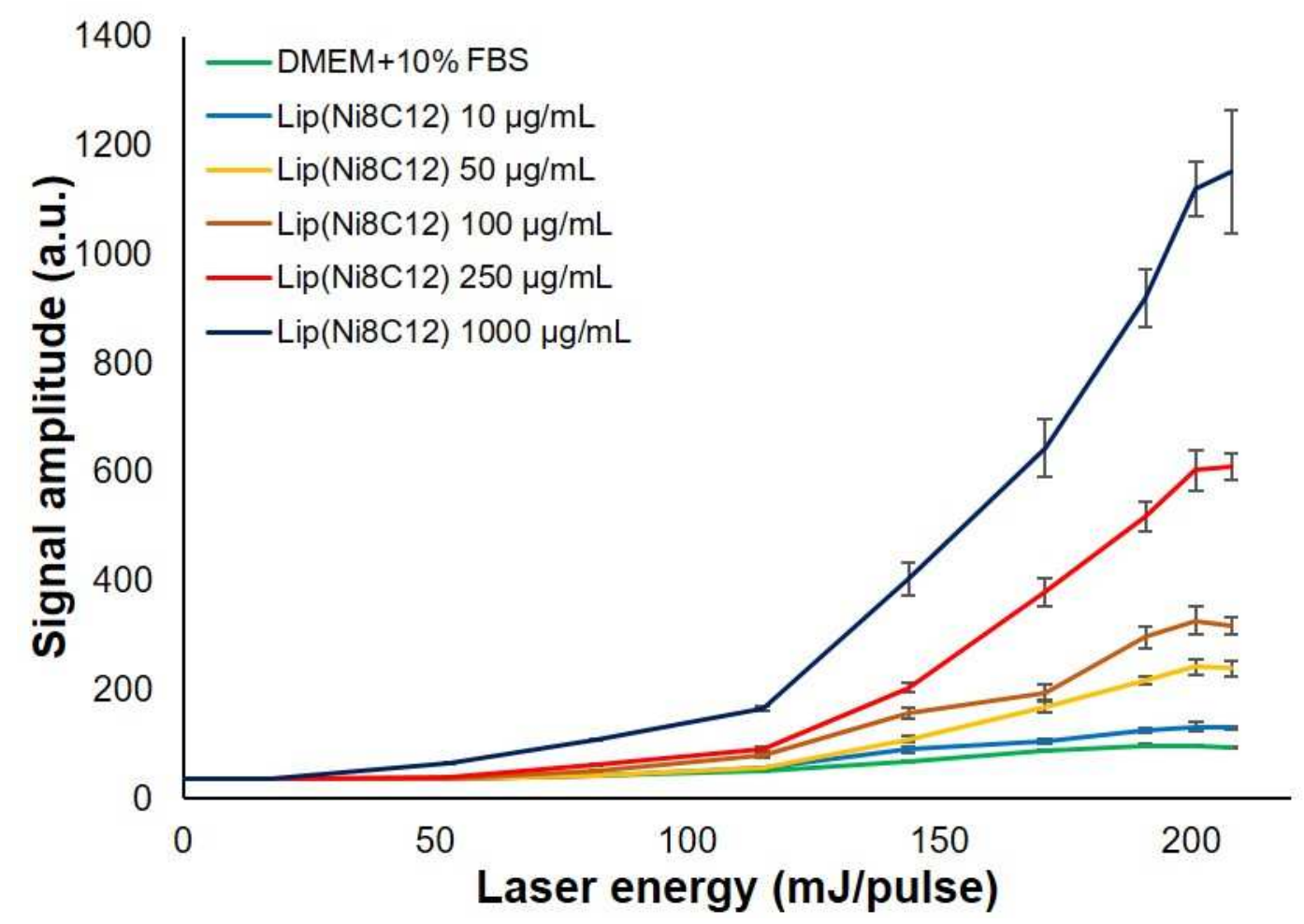

Figure 25. Photoacoustic signal detected depending on the power of laser pulses and on the liposome concentration in DMEM+10\% FBS medium (standard deviations calculated on 20 images). Reproduced from ref ${ }^{[51]}$, Copyright (2019), with permission from the American Chemical Society.

All these innovative and promising results demonstrate that metal-bis(dithiolene) complexes are attractive molecules to develop new theranostic systems. These results open up many perspectives for the development of new nanostructures for the treatment of diseases such as cancers by combining chemotherapy and phototherapy. It would now be important to carry out in vivo release studies while introducing targeting and selectivity. Biodistribution, biotransformation and clearance of the metal-complexes as well as their pharmacological specificities will also have to be considered and studied. 


\section{Conclusion}

The rational design of functional dithiolene ligands with carbon chains of various lengths and hydrogen bonding motifs (amides) has allowed the emergence of new mesophases with original symmetry over large temperature range. Depending on the nature of the metal, different properties can easily be imported inside such temperature-sensitive soft materials. For example, the magnetic response of paramagnetic gold-bis(dithiolene) complexes can easily be controlled at the phase transitions. The proper functionalization of the dithiolene ligands, for example with chiral cholesteryl fragments, has also allowed the development of new metallogelators with intriguing optical properties, especially in the NIR region, or magnetic properties, which can also be modulated by controlling the supramolecular aggregation state. Along these lines, it has been also demonstrated that metal-bis(dithiolene) complexes are very good photothermal agents with high thermal and optical stabilities. Furthermore, their optical properties (absorption band energy, absorption coefficient) can be easily modulated from the nature of the substituents and the actual electron count of the complexes. The photothermal properties can be used to disturb the molecular aggregation and to modulate the properties of the whole material. For example, optical data storage can be done by local pin-pointed laser irradiation onto liquid crystalline thin films. The photothermal properties of dithiolene complexes can also be exploited to stimulate liquid crystalline polymers to develop new actuators, optical conveyors or artificial muscles. The exceptional photothermal properties of metalbis(dithiolene) complexes in the NIR region is also a good opportunity to develop new agents for photothermal therapies or light-responsive organic nanoparticles for photo-controlled drug delivery. To address these issues, a control of the hydrophilic/lipophilic balance is a prerequisite which has been solved, for example through the functionalization with triethyleneglycol chains for proper water solubility. On the other hand, lipophilic complexes were used for introduction in lipid bilayer liposomes. Finally, our results have shown that dithiolene complexes also display good photoacoustic properties under laser irradiation which of great interest to develop new exogenous contrast agents for bio-imaging. All these recent works demonstrate the versatility of metal-bis(dithiolene) complexes making these complexes highly attractive to develop original stimuli-responsive soft materials with tunable properties, for dedicated applications in biotechnology but also in material science. 


\section{References}

[1] Dithiolene Chemistry: Syntheses, Properties and Applications, E. I. Stiefel Ed. Prog. Inorg. Chem., 2004, vol. 52.

[2] a) R. Kato, Chem. Rev., 2004, 104, 5319-5346; b) N. Robertson, L. Cronin, Coord. Chem. Rev., 2002, 227, 93-127. c) B. Garreau-de Bonneval, K. I. Moineau-Chane Ching, F. Alary, T.-T. Bui, L. Valade, Coord. Chem. Rev., 2010, 254, 1457-1467

[3] a) T. Naito, Bull. Chem. Soc. Jpn, 2017, 90, 89-136; b) T. Naito, Chem. Lett. 2018, 47, 1441-1452; c) T. Naito, in Functional Materials: Advances and Applications in Energy Storage and Conversion (465+xii pages), Chap. 1, pp. 1-82, T. Naito Ed., Pan Stanford Publishing Pte. Ltd., Singapore (2019).

[4] M. L. Kirk, R. L. McNaughton and M. E. Helton, in Dithiolene Chemistry: Syntheses, Properties and Applications, Prog. Inorg. Chem., 2004, 52, ch. 3, p. 111.

[5] B. S. Lim, D. M. Formitchev, R. H. Holm, Inorg. Chem., 2001, 40, 4257-4262.

[6] a) M. C. Aragoni, M. Arca, F. Demartin, F. A. Devillanova, A. Garau, F. Isaia, F. Lelj, V. Lippolis, G. Verani, J. Am. Chem. Soc., 1999, 121, 7098-7107C; b) C. Deiana, M. C. Aragoni, F. Isaia, V. Lippolis, A. Pintus, A. M. Z. Slawin, J. D. Woolins, M. Arca, New. J. Chem., 2016, 40, 8206-8210.

[7] a) N. Tenn, N. Bellec, O. Jeannin, L. Piekara-Sady, P. Auban-Senzier,, J. Iniguez, E. Canadell, D. Lorcy, J. Am. Chem. Soc., 2009, 131, 16961-16967; b) G. Yzambart, N. Bellec, G. Nasser, O. Jeannin, M. Fourmigué, P. Auban-Senzier, J. Íñiguez, E. Canadell, D. Lorcy, J. Am. Chem. Soc., 2012, 134, 17138-17148; c) H.Cui, H. Kobayashi, S. Ishibashi, M. Sasa, F. Iwase, R. Kato, A. Kobayashi, J. Am. Chem. Soc. 2014, 136, 76197622; d) B. Zhou, H. Yajima, Y. Idobata, A. Kobayashi, T. Kobayashi, E. Nishibori, H. Sawa, H. Kobayashi, Chemistry Letters 2012, 41, 154-156; e) B. Zhou, M. Shimamura, E. Fujiwara, A. Kobayashi, T. Higashi, E. Nishibori, M. Sakata, H. Cui, K. Takahashi, H. Kobayashi, J. Am. Chem. Soc. 2006, 128, 3872-3873; f) A. Kobayashi, E. Fujiwara, H. Kobayashi, Chem. Rev. 2004, 104, 5243-5264.

[8] a) K. Mebrouk, W. Kaddour, P. Auban-Senzier, C. Pasquier, O. Jeannin, F. Camerel, M. Fourmigué, Inorg. Chem. 2015, 54, 7454-7460; b) B. Zhou, M. Shimamura, E. Fujiwara, A. Kobayashi, T. Higashi, E. Nishibori, M. Sakata, H. Cui, K. Takahashi, H. Kobayashi, J. Am. Chem. Soc. 2006, 128, 3872-3873. 
[9] a) H. Cui, T. Tsumuraya, T. Miyazaki, Y. Okano, R. Kato. Eur. J. Inorg. Chem., 2014, 3837-3840; b) A. Filatre-Furcate, B. Bellec, O. Jeannin, P. Auban-Senzier, M. Fourmigué, A. Vacher, D. Lorcy, Inorg. Chem., 2014, 53, 8681-8690

[10] a) Jpn. Kokai Tokkyo Koho (1980), JP 55058588; b) K. Enmanji, K. Takahashi, H. Kusakawa, T. Ito, Jpn. Tokkyo Koho (1985), JP 60034833.

[11] E. Molva, J.-J. Aubert, J. Marty, J.-M. Nunzy, Eur. Pat. Appl. (1995), EP 653824

[12] a) K. L. Marshall, B. Schudel, I. A. Lippa, Proc. SPIE-The International Society for Optical Engineering, 2003, 5213, 201-212; b) K. L. Marshall, U.S. Patent (2009), US 7492439.

[13] a) U. T. Mueller-Westerhoff, B. Vance, D. I. Yoon, Tetrahedron, 1991, 47, 909-932; b)

U. T. Müller-Westerhoff, Abstracts of papers of the ACS, 2008, 236, 330-INOR.

[14] a) E. I. Altinoglu, J. H. Adair, Wiley Interdiscip. Rev.: Nanomed. Nanobiotechnol., 2010, 2, 461-477; b) Q. Tian, M. Tang, Y. Sun, R. Zou, Z. Chen, M. Zhu, S. Yang, J. Wang, J. Wang, J. Hu, Adv. Mater., 2011, 23, 3542-3547.

[15] S. Kawakami, Y. Kojima, Japan Kokai Tokkyo Koho, JP 04153086, A 19920526, 1992

[16] a) A. M. Giroud, U. T. Mueller-Westerhoff, Mol. Cryst., Liq. Cryst. Lett., 1977, 41, 1113; b) A. M. Giroud, Ann. Phys. 1978, 3, 147-150; c) A. M. Giroud, A. Nazzal, U.T. Mueller-Westerhoff, Mol. Cryst., Liq. Cryst. Lett., 1980, 56, 225-228; d) U. T. MuellerWesterhoff, A. Nazzal, R. J. Cox, A. M. Giroud, Mol. Cryst., Liq. Cryst. Lett., 1980, 56, $249-255$.

[17] B. Donnio, D. Guillon, R. Deschenaux, D. W. Bruce, Metallomesogens. In: Comprehensive Coordination Chemistry II. J. A. McCleverty \& T. J. Meyer Editors. Vol. 6. Oxford: Elsevier; 2003.

[18] R.W. McCabe, O. Llyr Parri, A. H. J. Price, Mater. Chem., 1993, 3, 609-613.

[19] a) H. Horie, A. Takagi, H. Hasebe, T. Ozawa, K. Ohta, J. Mater. Chem., 2001, 11, $1063-$ 1071; b) M. Veber, P. Davidson, C. Jallabert, A.M. Levelut, H. Strzelecka, Mol. Cryst. Liq. Cryst. Lett., 1988, 5, 1-7.

[20] a) K. Ohta, H. Hasebe, H. Ema, T. Fujimoto, I. Yamamoto, J. Chem. Soc., Chem. Commun., 1989, 1610-1611; b) K. Ohta, H. Hasebe, H. Ema, M. Moriya, T. Fujimoto, I. Yamamoto, Mol. Cryst. Liq. Cryst., 1991, 208, 21-32; c) K. Ohta, H. Hasebe, M. Moriya, T. Fujimoto, I. Yamamoto, Mol. Cryst. Liq. Cryst., 1991, 208, 33-41.

[21] K. Ohta, Y. Inagaki-Oka, H. Hasebe, I. Yamamoto, Polyhedron, 2000, 19, 267-274.

[22] J.-Y Cho, B. Domercq, S.C. Jones, J. Yu, X. Zhang, Z. An, M. Bishop, S. Barlow, S.R. Marder, B. Kippelen, J. Mater. Chem., 2007, 17, 2642-2647. 
[23] R. Perochon, P. Davidson, S. Rouzière, F. Camerel, L. Piekara-Sady, T. Guizouarn, M. Fourmigué, J. Mater. Chem., 2011, 21, 1416-1422.

[24] a) C. Piechocki, J. Simon, J.-J. André, D. Guillon, P. Petit, A. Skoulios, P. Weber, Chem. Phys. Lett., 1985, 122, 124-128; b) J.-J. André, M. Bernard, C. Piechocki, J. Simon, J. Phys. Chem., 1986, 90, 1327-1330; c) Z. Belarbi, C. Sirlin, J. Simon, J.-J. André, J. Phys. Chem., 1989, 93, 8105-8110; d) A.G. Gürek, T. Basova, D. Luneau, C. Lebrun, E. Kol'tsov, A.K. Hassan, V. Ahsen, Inorg. Chem., 2006, 45, 1667-1676; e) S. Kapuściński, A. Gardias, D. Pociecha, M. Jasiński, J. Szczytko, P. Kaszyński, J. Mater. Chem. C, 2018, 6, 3079-3088.

[25] a) Y. Takemoto, T. Yamamoto, N. Ikuma, Y. Uchida, K. Suzuki, S. Shimono, H. Takahashi, N. Sato, Y. Oba, R. Inoue, M. Sugiyama, H. Tsue, T. Kato, J. Yamauchia, R. Tamura, Soft Matter 2015, 11, 5563-5570; b) Y. Wang, M. Frasconi, J.F. Stoddart, ACS Cent. Sci. 2017, 3, 927-935; c) S.F. Medeiros, A.M. Santos, H. Fessi, A. Elaissari, Int. J. Pharmaceutics 2011, 403, 139-161.

[26] S. Debnath, H. S. Srour , B. Donnio, M. Fourmigué, F. Camerel, RSC Advances, 2012, 2, 4453-4462.

[27] S. Diring, F. Camerel, B. Donnio, T. Dintzer, S. Toffanin, R. Capelli, M. Muccini, R. Ziessel, J. Am. Chem. Soc., 2009, 131, 18177-18185.

[28] M. Ciancone, F. Camerel, Chem. Commun., 2017, 53, 6339-6342.

[29] K. Mebrouk, F. Camerel, O. Jeannin, B. Heinrich, B. Donnio, M. Fourmigué, Inorg. Chem., 2016, 55, 1296-1303.

[30] a) G.M. Whitesides, Angew. Chem. Int. Ed., 2018, 57, 4258 -4273; b) F. Schmitt, O. Piccin, L. Barbé, B. Bayle, Front. Robot. AI, 2018, 5, 84; c) A. Miriyev, K. Stack, H. Lipson, Nat. Commun., 2017, 8, 596.

[31] M. Cianchetti, C. Laschi, A. Menciassi, P. Dario, Nature Rev. Mater., 2018, 3, 143-153.

[32] L. Dong, Y. Zhao, Mater. Chem. Front., 2018, 2, 1932-1943.

[33] F. Ge, R. Yang, X. Tong, F. Camerel, Y. Zhao, Angew. Chem. Int. Ed., 2018, 56, 95469550.

[34] H.-C. Chang, K. Komasaka, K. Kishida, T. Shiozaki, T. Ohmori, T. Matsumoto, A. Kobayashi, M. Kato, S. Kitagawa, Inorg. Chem., 2011, 50, 4279-4288.

[35] F. Camerel, G. Albert, F. Barrière, C. Lagrost, M. Fourmigué, O. Jeannin, Chem. Eur. J., 2019, 25, 5719-5732.

[36] a) R. G. Weiss, P. Terech, Molecular Gels, Materials With Self-Assembled Fibrillar Networks, Springer, Dordrecht, 2006; b) S. Banerjee, R. K. Das, U. Maitra, J. Mater. Chem., 2009, 19, 6649-6687. 
[37] a) M.-O. M. Piepenbrock, G. O. Lloyd, N. Clarke, J. W. Steed, Chem. Rev., 2010, 110, 1960-2004; b) J. Zhang, C.-Y. Su, Coord. Chem. Rev., 2013, 257, 1373-1408.

[38] S. Debnath, J.-F. Bergamini, F. Artzner, C. Mériadec, F. Camerel, M. Fourmigué, Chem Commun., 2012, 48, 2283-2285

[39] A. Ajayaghosh, C. Vijayakumar, R. Varghese, and S. J. George, Angew. Chem. Int. Ed., 2006, 118, 470-474.

[40] K. Mebrouk, S. Debnath, M. Fourmigué, F. Camerel, Langmuir, 2014, 30, 8592-8597.

[41] Q. Li (Ed.), Photoactive Functional Soft Materials: Preparation, Properties, and Applications, Wiley-VCH, Weinheim, 2018 (ISBN 978-3-527-34482-6).

[42] M. Gao, L. Zhu, C.K. Peha, G.W. Ho, Energy Environ. Sci., 2019, 12, 841-864.

[43] Y. Liu, P. Bhattarai, Z. Dai, X. Chen, Chem. Soc. Rev., 2019, 48, 2053-2108.

[44] H.S. Jung, P. Verwilst, A. Sharma, J. Shin, J.L. Sessler, J.S. Kim, Chem. Soc. Rev., 2018, $47,2280-2297$

[45] a) M. Khafaji, M. Zamani, M. Golizadeh, O. Bavi, Biophys Rev., 2019, 11, 335-352; b) Z. Bao, X. Liu, Y. Liu, H. Liu, K. Zhao, Asian J. Pharm. Sci., 2016, 11, 349-364.

[46] K. Mebrouk, F. Chotard, C. Le Goff-Gaillard, Y. Arlot-Bonnemains, M. Fourmigué, F. Camerel, Chem. Commun., 2015, 51, 5268-5270.

[47] D. Jaque, L. Martínez Maestro, B. del Rosal, P. Haro-Gonzalez, A. Benayas, J. L. Plaza, E. Martín Rodríguez, J. García Solé, Nanoscale, 2014, 6, 9494-9530.

[48] M. Ciancone, K. Mebrouk, N. Bellec, C. Le Goff-Gaillard, Y. Arlot-Bonnemains, T. Benvegnu, M. Fourmigué, F. Camerel, S. Cammas-Marion, J. Mater. Chem. B, 2018, 6, 1744-1753.

[49] a) P. Loyer, S. Cammas-Marion, J. Drug Targeting, 2014, 22, 556-575; b) S. Cammas, M.M. Bear, A. Harada, P. Guérin, K. Kataoka, Macromol. Chem. Phys., 2000, 201, $355-$ 364; c) Z.W. Huang, V. Laurent, G. Chetouani, J.Y. Ljubimova, E. Holler, T. Benvegnu, P. Loyer, S. Cammas-Marion, Int. J. Pharmaceutics, 2012, 423, 83-92.

[50] K. Mebrouk, T. Vives, S. Cammas-Marion, T. Benvegnu, C. Le Goff-Gaillard, Y. ArlotBonnemains, M. Fourmigué, F. Camerel, ChemMedChem, 2017, 12, 1753-1758.

[51] M. Ciancone, N. Bellec, S. Cammas-Marion, A. Dolet, D. Vray, F. Varray, C. Le GoffGaillard, X. Le Goff, Y. Arlot-Bonnemains, F. Camerel, Langmuir, 2019, 35, 1512115130 . 


\section{For Table of Content:}

Key topic: Stimulatable dithiolene complexes

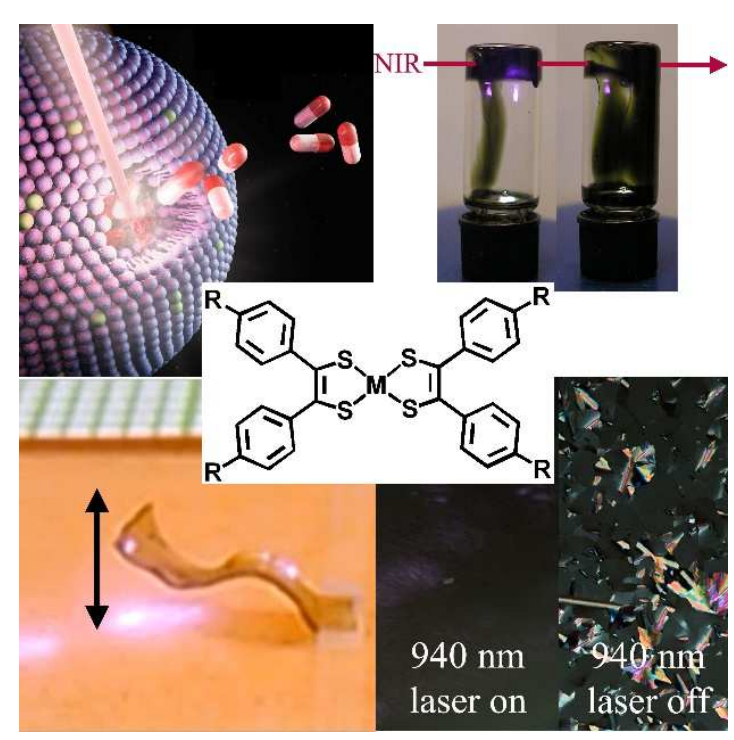

Proper functionalization of metal-bis(dithiolene) complexes allow for the development of stimuli-responsive soft materials for applications in biotechnologies and materials science. 